\title{
Article \\ Comparative Analysis of Transcriptome and sRNAs Expression Patterns in the Brachypodium distachyon-Magnaporthe oryzae Pathosystems
}

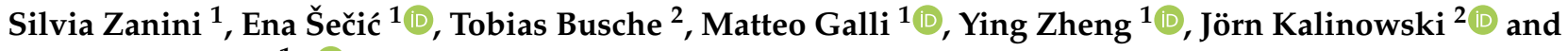 \\ Karl-Heinz Kogel 1,*(D) \\ 1 Institute of Phytopathology, Centre for BioSystems, Land Use and Nutrition, Justus Liebig University (iFZ), \\ 35392 Giessen, Germany; Silvia.F.Zanini@agrar.uni-giessen.de (S.Z.); Ena.Secic@agrar.uni-giessen.de (E.Š.); \\ Matteo.Galli@agrar.uni-giessen.de (M.G.); Ying.Zheng@agrar.uni-giessen.de (Y.Z.) \\ 2 Center for Biotechnology (CeBiTec), Bielefeld University, 33615 Bielefeld, Germany; \\ tbusche@cebitec.uni-bielefeld.de (T.B.); joern@cebitec.uni-bielefeld.de (J.K.) \\ * Correspondence: Karl-Heinz.Kogel@agrar.uni-giessen.de
}

check for updates

Citation: Zanini, S.; Šečić, E.; Busche, T.; Galli, M.; Zheng, Y.; Kalinowski, J.; Kogel, K.-H. Comparative Analysis of Transcriptome and sRNAs Expression Patterns in the Brachypodium distachyon-Magnaporthe oryzae Pathosystems. Int. J. Mol. Sci. 2021, 22, 650. https://doi.org/ $10.3390 /$ ijms 22020650

Received: 14 December 2020 Accepted: 1 January 2021 Published: 11 January 2021

Publisher's Note: MDPI stays neutral with regard to jurisdictional clai$\mathrm{ms}$ in published maps and institutional affiliations.

Copyright: (C) 2021 by the authors. Licensee MDPI, Basel, Switzerland. This article is an open access article distributed under the terms and conditions of the Creative Commons Attribution (CC BY) license (https:// creativecommons.org/licenses/by/ $4.0 /)$.

\begin{abstract}
The hemibiotrophic fungus Magnaporthe oryzae (Mo) is the causative agent of rice blast and can infect aerial and root tissues of a variety of Poaceae, including the model Brachypodium distachyon (Bd). To gain insight in gene regulation processes occurring at early disease stages, we comparatively analyzed fungal and plant mRNA and sRNA expression in leaves and roots. A total of 310 Mo genes were detected consistently and differentially expressed in both leaves and roots. Contrary to Mo, only minor overlaps were observed in plant differentially expressed genes (DEGs), with 233 Bd-DEGs in infected leaves at 2 days post inoculation (DPI), compared to 4978 at 4 DPI, and 138 in infected roots. sRNA sequencing revealed a broad spectrum of Mo-sRNAs that accumulated in infected tissues, including candidates predicted to target Bd mRNAs. Conversely, we identified a subset of potential Bd-sRNAs directed against fungal cell wall components, virulence genes and transcription factors. We also show a requirement of operable RNAi genes from the DICER-like (DCL) and ARGONAUTE (AGO) families for fungal virulence. Overall, our work elucidates the extensive reprogramming of transcriptomes and sRNAs in both plant host $(\mathrm{Bd})$ and fungal pathogen $(\mathrm{Mo})$, further corroborating the critical role played by sRNA species in the establishment of the interaction and its outcome.
\end{abstract}

Keywords: argonaute; dicer; RNAi; plant disease; small RNA; virulence; gene expression

\section{Introduction}

The ascomycete fungus Magnaporthe oryzae (Mo) (anamorph: Pyricularia grisea) is the causal agent of rice blast, one of the most devastating and widespread diseases of cultivated rice, reducing yields up to $30 \%$ annually [1-3]. Members of the Magnaporthe genus can also infect a variety of other cereals, including barley, rye and wheat, making Mo a major threat to global food security [4,5]. Currently, blast management strategies rely on a combination of fungicide applications (e.g., azoles), development of resistant cultivars, and agronomic practices such as removal of crop residues, water management and crop/land rotation [6,7].

In the early stage of foliar infection Mo behaves as a biotroph, forming a biotrophic interfacial complex (BIC) between the primary invasive hyphae (derived from the penetration peg) and the infected host cell, where it secretes small molecules (effectors) to modulate the interaction $[8,9]$. Subsequently the fungus forms secondary hyphae and spreads to neighboring cells, undertaking a lifestyle change switching to a necrotrophic growth, with the appearance of the characteristic blast lesions on leaves [5]. Mo is able to infect all aerial parts of rice including nodes, panicles and necks, and has been shown to produce necrotic lesions on both rice and barley roots, although its lifestyle in roots seems to depend on the inoculation method $[4,10]$. Mo infections have also been established 
in Brachypodium distachyon (Bd), which has been proposed as a model for cereals as it is preferable for research over more complex crops such as wheat and barley [11,12]. Bd has a smaller genome (272 Mb in Bd21-3 v1.0 assembly) with low genome complexity, a short life cycle, simple growth requirements and a vast T-DNA insertion library available [13-15].

Small RNAs (sRNAs), such as small interfering RNAs (siRNAs) and micro RNA (miRNAs), are systemic signals that modulate distal gene regulation and epigenetic events in response to biotic and abiotic environmental cues in plants [16-18]. Particularly, sRNAmediated gene silencing is one of the main defense mechanisms against viral attack and genome damaging effects of transposons. The action of sRNAs rests upon their role in RNA interference (RNAi), a conserved mechanism of gene regulation in eukaryotes at the transcriptional (TGS or transcriptional gene silencing) and post-transcriptional (PTGS or post-transcriptional gene silencing) levels [19-21]. In plants, the trigger for RNAi is either endogenous or exogenous (e.g., viral) double-stranded RNA (dsRNA) or hairpin RNA (hpRNA) that is processed into short 20 to 24 nucleotide (nt) double-stranded sRNAs by DICER-like (DCL) enzymes [22,23]. These sRNAs are incorporated into an RNA-induced silencing complex (RISC), containing an RNAse III-type endonucleolytic ARGONAUTE (AGO) protein to target complementary RNAs for degradation/inhibition or epigenetic modification by RNA-dependent DNA methylation (RdDM), histone modification and chromatin remodeling. Additionally, secondary sRNAs are generated in plants by RNAdependent RNA polymerases (RdRPs) [21,24].

The genome of Mo encodes a complete RNAi machinery, comprised of two DCL genes, three $A G O$ genes and three RdRP genes [25-27]. Knock-out (KO) of RNAi pathway components severely affected sRNA production in axenic culture, with deletion of MoDCL2, MoRdRP2 and MoAGO3 genes reducing sRNA expression levels. In particular, MoDCL2, but not MoDCL1, was necessary for siRNA production from dsRNA precursor molecules [27]. Of note, loss of MoAGO3 and MoRdRP1 function reduced both sRNAs and fungal virulence on barley leaves. sRNA-mediated alterations of TGS and PTGS have been detected in vitro both during starvation/different nutrient availability, and in planta during different stages of rice leaf infection [27]. Additionally, Mo sRNAs differentially accumulate in mycelia and appressoria [28], further supporting the notion that sRNAs regulate Mo's development, growth and virulence. Similar to Mo, the formation of endogenous sRNAs in $\mathrm{Bd}$ is also subject to changes in response to external factors, where miRNAs have been proven to vary during exposure to abiotic stress and between vegetative vs. reproductive tissues [29], pointing to operable RNAi-based regulatory mechanisms in the model grass [30]. A total of $328 \mathrm{Bd}$ miRNA precursor sequences have been identified so far and deposited in the miRBase database, corresponding to 536 mature miRNAs with predicted regulatory functions in cold [31], heat [32] and drought stress [33] and morphological alterations [34]. While knowledge about the RNAi machinery of Bd is not comprehensive and there is currently no data on RNAi KO mutants available from this organism, our recent work characterized the major RNAi genes in silico, resulting in 16 BdAGO-like and six BdDCL candidates [35]. Thus, the study showed that the RNAi machinery follows the trend that cereals have extended families of key enzymes involved in RNAi.

Consistent with the exchange of RNAs during animal-parasitic interactions [36-38], sRNAs are also exchanged in host plant-pathogen interactions. The plant-pathogenic fungus Verticillium dahliae $(\mathrm{Vd})$ accumulated plant miRNAs when recovered from infected cotton samples, indicating that host-derived sRNAs were transmitted into the pathogen during infection [39]. Two of those cotton miRNAs, miR166 and miR159, target the fungal genes Ca2+-dependent cysteine protease calpain (VdClp-1) and isotrichodermin C-15 hydroxylase (VdHiC-15), respectively, which are known to contribute to fungal virulence. Similarly, Arabidopsis cells secrete vesicles to deliver sRNAs into grey mold fungal pathogen Botrytis cinerea $(\mathrm{Bc})$, where they cause silencing of fungal genes critical for pathogenicity [40]. Consistent with the bidirectional move of sRNAs in plant-microbe interactions, Bc also produces sRNA effectors that downregulate Arabidopsis and tomato genes involved in 
immunity [41]. Some of these sRNAs, for example Bc-siR37, downregulate a large set of host immunity genes to enhance Bc pathogenicity [42].

Here we investigate the induction of sRNAs and transcriptome changes in the early stages of interaction of $\mathrm{Bd}$ and Mo based on data generated by parallel sequencing of sRNA and mRNA from infected leaf and root tissues. Using a previously published bioinformatics pipeline to characterize sRNA and its targets [43], we predict potential sRNA effectors whose targets were downregulated in the respective recipient organism.

\section{Results}

2.1. Requirement for Functional RNAi Genes in the Interaction of Brachypodium distachyon Bd21-3 and Magnaporthe oryzae 70-15

The Magnaporthe oryzae (Mo) 70-15 genome encodes three putative AGO and two DCL proteins, previously identified by domain search and phylogeny with known Neurospora crassa $(\mathrm{Nc})$ RNAi machinery genes [25-27]. The corresponding protein sequences were obtained from NCBI: XP_003714515.1 (MGG_01541T0, MoDCL1), XP_003715365.1 (MGG_12357T0, MoDCL2), XP_003716704.1 (MGG_14873T0, MoAGO1), XP_003717504.1 (MGG_13617T0, MoAGO2) and XP_003714217.1 (MGG_01294T0, MoAGO3); they were included in new phylogenetic trees to corroborate previous findings (Figure S1A,B). To assess the conservation of key AGO and DCL domains, prediction was carried out with Simple Modular Architecture Research Tool (SMART). All three AGOs have conserved domain structures with five characteristic domains: N-terminal domain, DUF1785, PAZ (Piwi Argonaut and Zwille), L2 and PIWI (P-element Induced WImpy testis) (Figure S1C; Table S1). Additionally, multiple sequence alignment (MSA) confirmed the conservation of the DEDD catalytic tetrad (Asp/Glu/Asp/Asp) and the QF-V motif (Glu/Phe/Val) in the MoAGO PIWI domains (Figure S2). Likewise, both MoDCLs have the four conserved domains required for the cleavage of dsRNAs: DEXDc, HELICc, dicer-dimer and RIBOc (Figure S1D; Table S1). Subcellular localization of MoAGOs and MoDCLs was assessed using PSI-predictor; MoDCL1, MoAGO1 and MoAGO3 were predicted to primarily localize in the nucleus, while MoDCL2 and MoAGO2 were predicted to primarily localize in the cytosol. MoAGO1 and MoAGO2 also had secondary predicted localizations, the first in the cytosol and the second in plastids (Table S2).

Protein interaction analysis with STRING did not highlight any experimentally proven interaction for MoAGO and MoDCL proteins, but probable interactions could be inferred from data derived from homologs, found to either interact or co-express with several proteins in other species (Table S3A,B). In particular, all MoAGOs were predicted to interact with the two MoDCL proteins, a U5 small nuclear ribonucleoprotein component (MGG_13500) and a cell cycle control protein cwf14 (MGG_06309). For MoAGO1, additional interaction was predicted with Pumilio-family RNA-binding repeat protein (MGG_03158), ATP-dependent RNA helicase DED1 (MGG_02762), high-affinity glucose transporter (MGG_13651) and four uncharacterized proteins. In addition to interaction with AGO proteins, both fungal MoDCLs were predicted to interact with ATP-dependent DNA helicase MPH1 (MGG_04429), 30S ribosomal protein S16 (MGG_02598), WD domaincontaining protein (MGG_06727) and three uncharacterized proteins.

3D protein structure modeling for both MoDCL and MoAGO was performed with SWISS-MODEL. While no acceptable QMEAN Z-scores $(>-4)$ values were obtained for the two DCLs and AGO2 models due to the lack of suitable reference structures, two models for AGO1 (model 1 based on hAGO1, GMQE $=0.52$ QMEAN $=-3.98$ and model 3, based on hAGO2, GMQE $=0.51$ QMEAN $=-3.31$ ) and model 6 for AGO3 (based on hAGO4 template, $\mathrm{GMQE}=0.46 \mathrm{QMEAN}=-3.50$ ) passed the first quality check and were further validated with PROCHECK and WHATCHECK. Model 1 of AGO1 had a higher percentage of residues in the core region of the Ramachandran plot $(88.4 \%)$ and a better Ramachandran Z-score (-1.808) compared to model 3 ( $87.6 \%$ and -1.531 Z-score), while the AGO3 model scored $86.7 \%$ and -2.088 , respectively. As a result, model 1 of AGO1 and model 6 of AGO3 were selected as the best models and visualized with PyMOL (Figure 1A,B). 


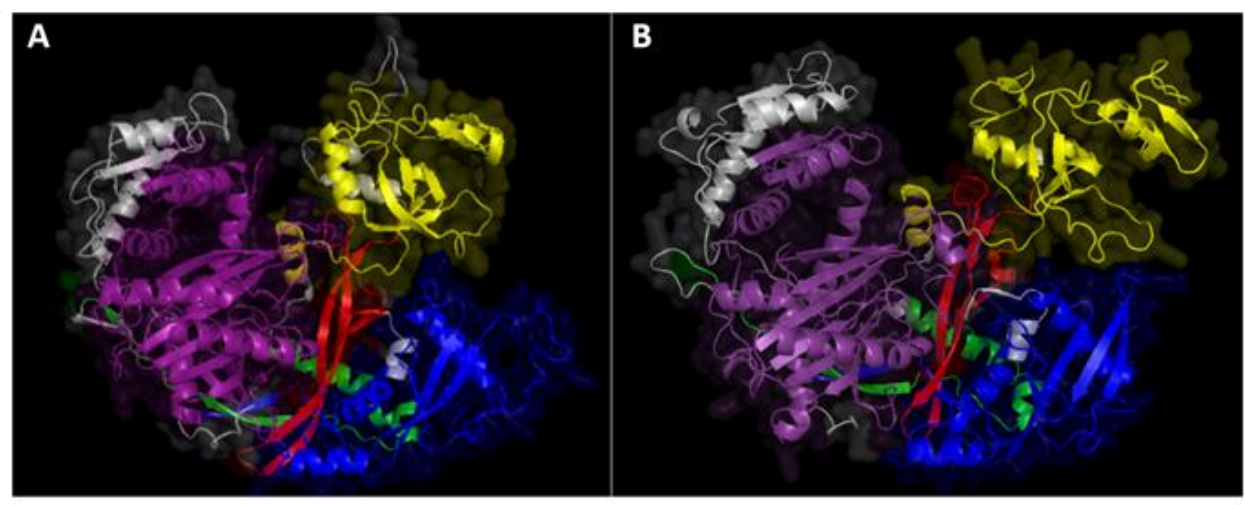

Figure 1. Predicted 3D structures of (A) M. oryzae MoAGO1 and (B) MoAGO3. Structures were modeled with SWISS-MODEL and domains were highlighted with PyMOL: blue = N-domain, red = DUF1785, yellow = PAZ (Piwi Argonaut and Zwille), green = L2, purple = PIWI (P-element Induced WImpy testis), the rest of the sequence with no domain predicted is colored in grey.

Next, we assessed the virulence of $\Delta$ moago1, $\Delta$ moago2, $\Delta \operatorname{modcl1}, \Delta \bmod l 2$ and the double mutant $\Delta \bmod c 1 / 2$ using Bd21-3 as a host. Negative effects on vitality of the five mutants vs. Mo wildtype (wt) could not be detected when inspecting conidia germination and appressorium formation on poly-L-lysine coated glass slides by $24 \mathrm{~h}$ after the onset of germination (Figure S3). In contrast, virulence of these mutants was compromised both on Bd leaves and roots (Figure S4). Since we expected differences in infection phenotypes depending on test conditions, three different leaf inoculation protocols were tested: (i.) upon drop inoculation of detached leaves all mutants showed significant (Kruskal-Wallis test, $p<0.05)$ reduction in necrotic lesion size, ranging from a $-20 \%$ to $-48 \%$ reduction of relative necrotic area compared to Mo wt ( $\Delta$ moago1 $-48 \%$; $\Delta$ moago $2-32 \%$; $\Delta$ modcl1 $-39 \%$; $\Delta \bmod l 2-24 \%$; $\Delta$ modcl1/2 -20\%; Figure 2A); (ii.) upon spray inoculation of detached leaves, virulence of $\Delta$ moago1 and $\Delta$ modcl1 was virtually unaffected as they showed the typical necrotic lesions at 5 days post inoculation (DPI), compared to $\Delta$ moago $2, \Delta \operatorname{modcl} 2$ and $\Delta$ modcl1/2, showing significantly reduced necrotic lesion areas (compared to Mo wt: $\Delta$ moago $-40 \%$; $\Delta$ modcl2 $-83 \%$; $\Delta$ modcl1/2 -68\% necrotic lesion sizes; Figure $2 \mathrm{~B}$ ); (iii.) similar phenotypes were observed in the whole seedling spray assay, with the exception of $\Delta$ modcl 2 and $\Delta$ modcl $1 / 2$ that appeared avirulent and did not show any detectable lesions (reduction in the necrotic lesion size compared to Mo wt: $\Delta$ moago $-79 \%$; $\Delta$ modcl2 $-100 \%$; $\Delta \operatorname{modcl} 1 / 2-100 \%$; Figure $2 \mathrm{C}$ ). Finally, mutants were inoculated on Bd roots and fungal presence was measured at 5 DPI by qPCR based on the fungal actin. All mutants showed a significant reduction in fungal biomass, with $\Delta$ moggo $2, \Delta \operatorname{modcl} 2$ and $\Delta$ modcl1/2 being the most severely affected (reduction in MoActin levels compared to wt: $\Delta$ moago1 $-70 \%$; $\Delta$ moago $-78 \%$; $\Delta$ modcl1 $-47 \%$; $\Delta \bmod l 2-87 \%$; $\Delta$ modcl1 $/ 2-87 \%$; Figure $2 \mathrm{D})$. These results confirm and extend previous findings that Mo's RNAi machinery is required for disease development in cereals and, in particular, that DCL2 is a key factor not only for sRNA biogenesis but also for fungal virulence. 
A

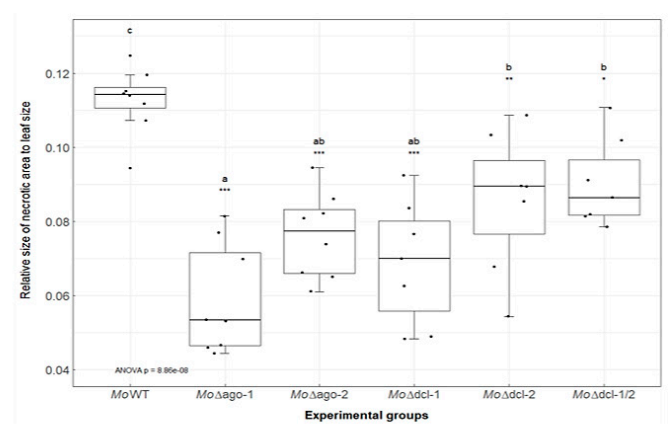

C

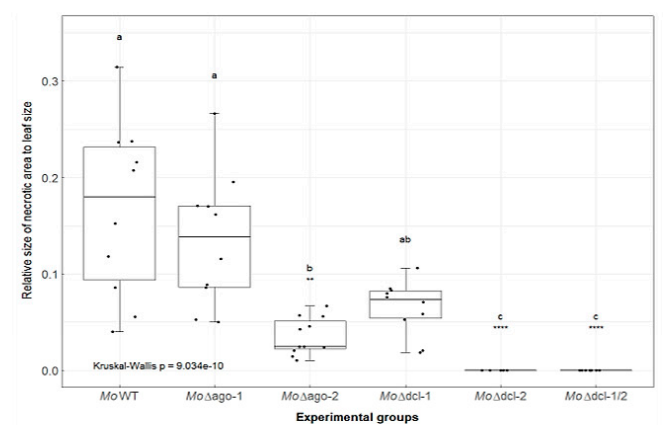

B

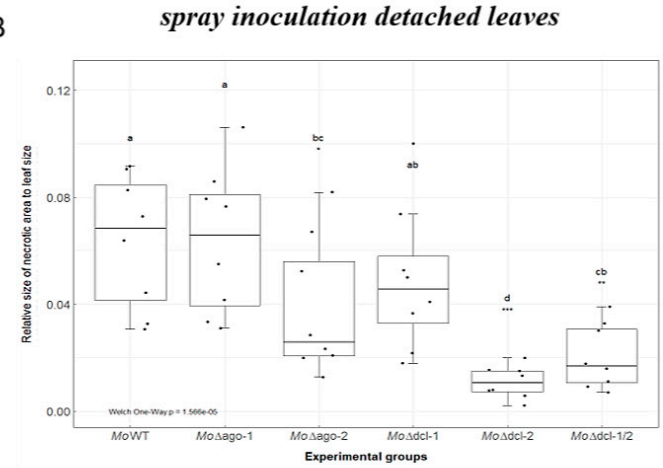

D

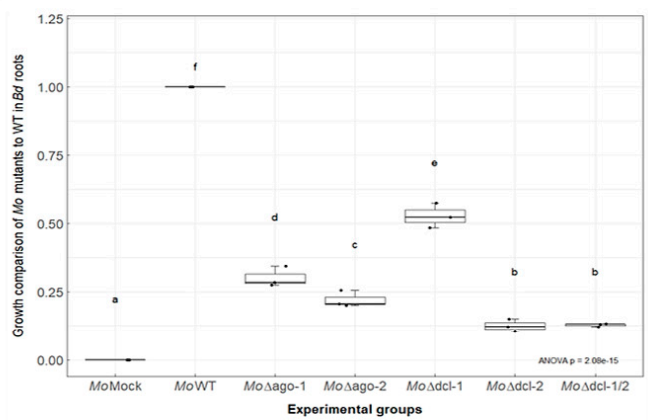

Figure 2. Infection assays of M. oryzae RNAi mutants. (A) Detached second youngest leaves of three-week-old Bd seedlings were drop inoculated with $10 \mu \mathrm{L}$ Mo conidia suspension $50 \times 10^{3}$ spores $\mathrm{mL}^{-1}$ in $0.002 \%$ Tween20 and kept under high humidity at $16 \mathrm{~h} \mathrm{light} / 8 \mathrm{~h}$ dark cycle at $22{ }^{\circ} \mathrm{C} / 18^{\circ} \mathrm{C}$. Fungal pathogenicity was assayed via ImageJ software at $5 \mathrm{DPI}$. The experiment was conducted two times ( $n=8$ plants per experimental group) with similar results. Comparisons between groups was performed via ANOVA and Tukey's range test for multiple comparisons. (B) Detached Bd leaves were spray inoculated with a total of $250 \mu \mathrm{L}$ Mo conidia suspension $50 \times 10^{3}$ spores $\mathrm{mL}^{-1}$ in $0.002 \%$ Tween20 and kept and evaluated as in (A). The experiment was conducted two times ( $n=8$ plants per experimental group) with similar results. Comparisons between groups was performed via Welch one-way test coupled with pairwise t-tests with Benjamini-Hochberg $p$-value adjustment. (C) Three-week-old Bd seedlings were spray inoculated with Mo conidia suspension $120 \times 10^{3} \mathrm{spores}^{\mathrm{mL}}-1$ in $0.002 \%$ Tween 20 and kept and evaluated as in (A). The experiment was conducted two times $(n=18$ plants per experimental group) with similar results. Comparisons between groups was performed via Kruskal-Wallis test and Dunn's test of multiple comparisons. (D) Roots of seven-day-old Bd seedlings were inoculated with $1 \mathrm{~mL}$ of Mo conidia suspension $125 \times$ $10^{3}$ spores $\mathrm{mL}^{-1}$ in $0.002 \%$ Tween 20 for $3 \mathrm{~h}$. Afterwards, seedlings were transplanted in small pots $(3 \mathrm{~cm} \varnothing)$ and grown for an additional 5 days before harvesting. Fungal amount was calculated by qPCR based on the ratio of fungal actin (MoActin). The experiment was conducted two times ( $n=6$ roots per experimental group) with similar results. Comparisons between groups was performed via ANOVA and Tukey's range test for multiple comparisons. (A-D) Letters represent statistical difference among all groups' means $(\alpha<0.05)$. Asterisks represent statistical difference of each group against wildtype (wt) $\left({ }^{*} p<0.05 ;{ }^{* *} p<0.01 ;{ }^{* * *} p<0.001 ;{ }^{* * *} p<0.0001\right)$.

\subsection{Differentially Expressed Genes (DEGs) in the Early Stages of Leaf and Root Infections}

TruSeq ${ }^{\circledR}$ Stranded mRNA libraries were produced from (i.) Mo axenic culture, (ii.) Mo-infected and mock-treated Bd roots (4 DPI) and (iii.) Mo-infected and mock-treated Bd leaves (2 DPI and 4 DPI) (Figure 3). These early time points were chosen to assess gene expression patterns both in the foliar biotrophic and necrotrophic growth phase of hemibiotrophic Mo [5]. mRNAseq analysis revealed a total of 233 Bd-DEGs (Wald test, Benjamini-Hochberg $(\mathrm{BH})$ adjustment, adjusted $p$-value (padj) $<0.05)$ in leaves at 2 DPI (224 upregulated and 9 downregulated), compared to 4978 at 4 DPI (3023 upregulated and 1955 downregulated) and 128 in roots (89 upregulated and 39 downregulated) (Figure 4; Table 1; Figure S5). 

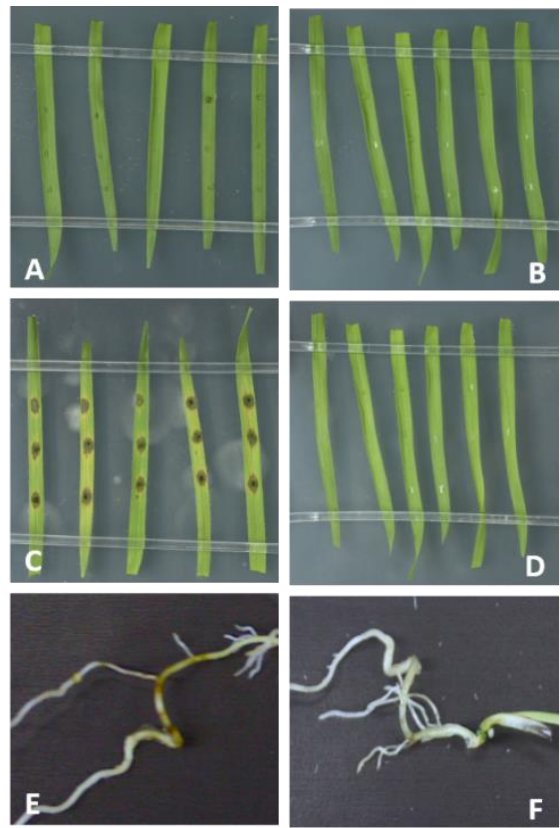

Figure 3. Brachypodium blast caused by M. oryzae Mo 70-15 on leaves and roots of $B$. distachyon Bd21-3. (A,D) Detached 21-day-old Bd leaves were drop-inoculated with $10 \mu \mathrm{L}$ of Mo suspension (50,000 conidia/mL) and kept for (A) 2 and (C) 4 days at high humidity, or mock-inoculated (B,D) with Tween water. Roots of 7-day-old Bd seedlings were (E) drop-inoculated with $1 \mathrm{~mL}$ of Mo suspension $(250,000$ conidia $/ \mathrm{mL})$ or $(\mathbf{F})$ mock-inoculated or and kept for 4 days under high humidity at $16 \mathrm{~h}$ light $/ 8 \mathrm{~h}$ dark cycle at $22{ }^{\circ} \mathrm{C} / 18^{\circ} \mathrm{C}$.
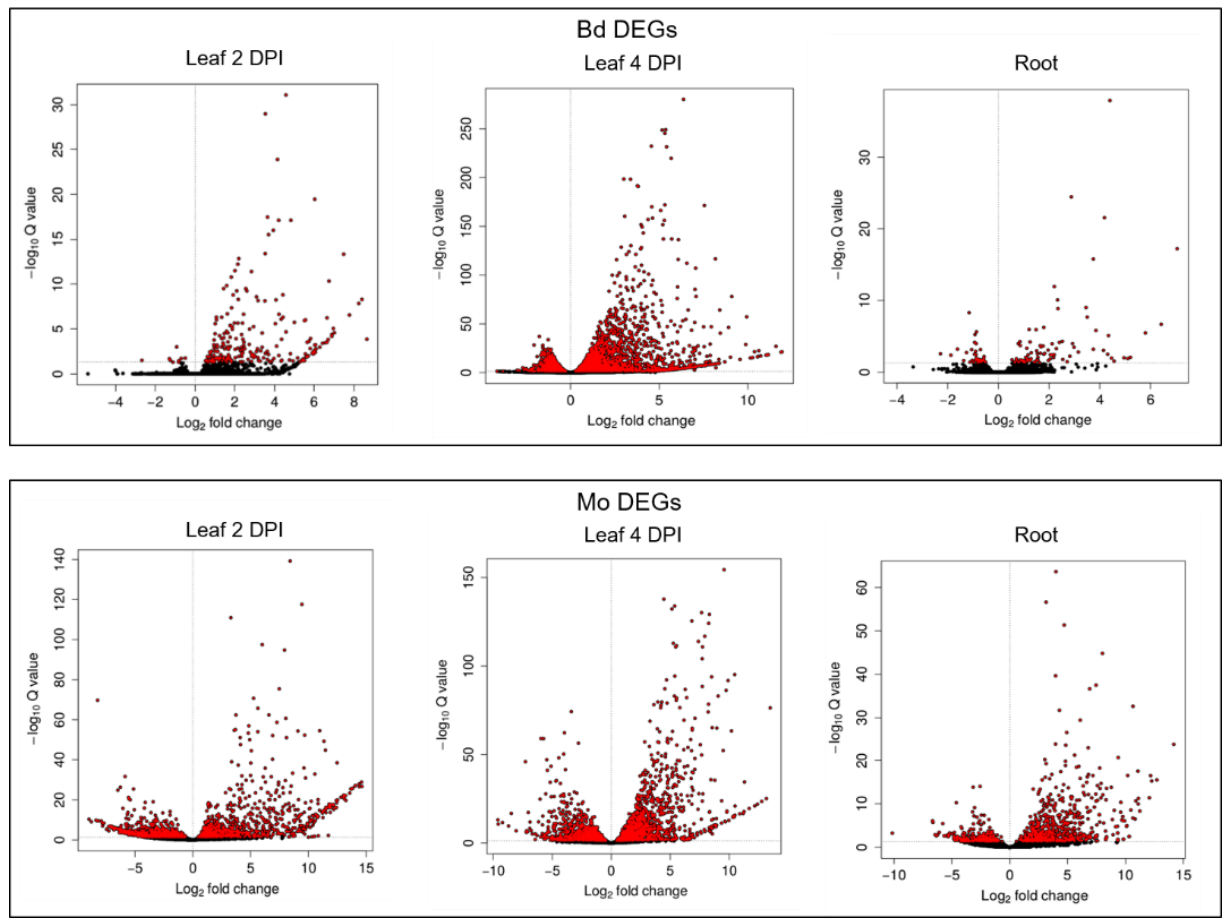

Figure 4. Volcano plots of DESeq2 results based on mRNAseq analysis of M. oryzae-infected leaves and roots of B. distachyon vs. control. Differentially expressed genes (DEGs) are highlighted in red with significant adjusted $p$-values (padj $<0.05$ ). 
Table 1. Total numbers of significantly (padj < 0.05) upregulated or downregulated genes in the B. distachyon-M. oryzae interaction.

\begin{tabular}{ccccc}
\hline Setup & $\begin{array}{c}\text { Total Mo Genes } \\
(\mathbf{U p})\end{array}$ & $\begin{array}{c}\text { Total Mo Genes } \\
\text { (Down) }\end{array}$ & $\begin{array}{c}\text { Total Bd Genes } \\
\text { (Up) }\end{array}$ & $\begin{array}{c}\text { Total Bd Genes } \\
\text { (Down) }\end{array}$ \\
\hline Leaf 2 DPI & 1041 & 1094 & 224 & 9 \\
\hline Leaf 4 DPI & 1710 & 1476 & 3023 & 1955 \\
\hline Root & 673 & 327 & 89 & 39
\end{tabular}

Overview of DESeq2 results. DESeq2 test for differential expression based on negative binomial distribution. Abbreviation: DPI $=$ days post inoculation.

Minor overlaps were observed comparing downregulated Bd genes between the biological setups, with only two shared between the foliar infections, and five between the leaf (4 DPI) and the root setup (Figure 5A). Among the upregulated genes, the highest overlap was seen between the foliar infections, sharing 134 DEGs, compared to 16 DEGs shared between root and leaf 2 DPI, and 72 between root and leaf 4 DPI (Figure 5B). Interestingly, $15 \mathrm{Bd}$ genes were upregulated in all setups, including defense-related $A B C$ transporter (BdiBd21-3.3G0465100.1), anthranilate synthase component II (BdiBd21-3.5G0159100.1), protein kinase xa21 (BdiBd21-3.3G0144800.1) and secologanin synthase-like (BdiBd21-3.2G0563800.1) (Table 2).

A

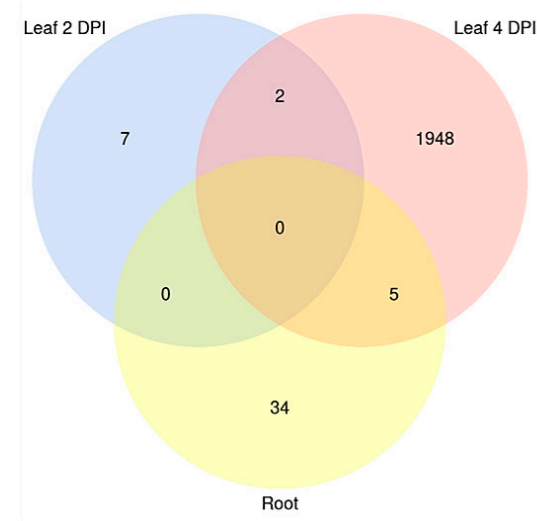

C

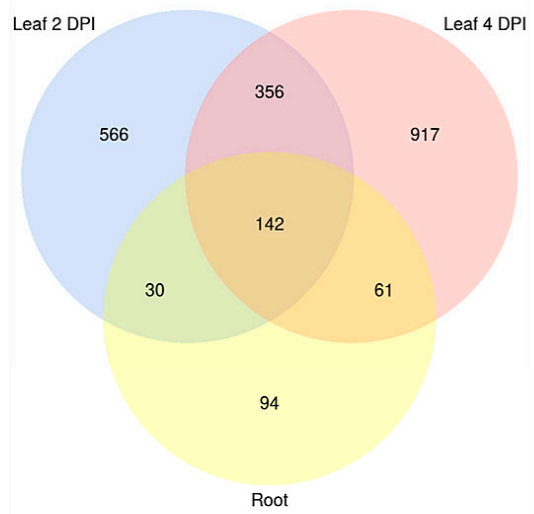

B

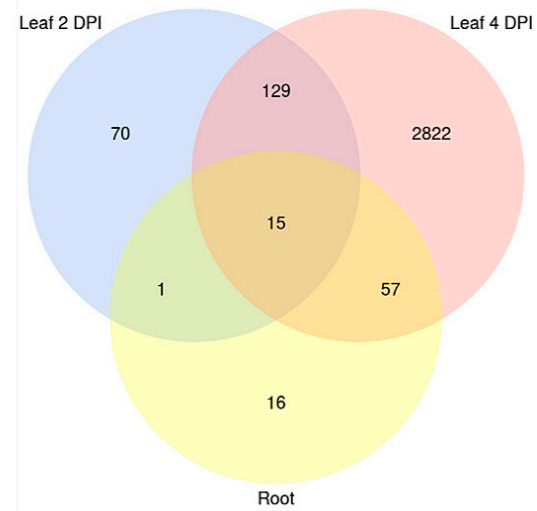

D

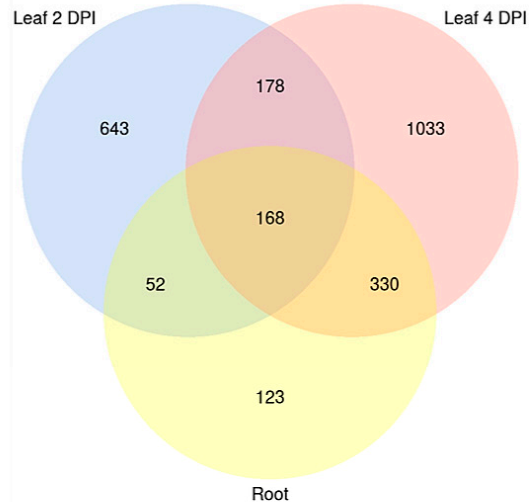

Figure 5. Venn diagram of differentially expressed B. distachyon and M. oryzae genes. Significantly (A) downregulated (fold change $(\mathrm{FC})<0$ padj $<0.05)$ and $(\mathbf{B})$ upregulated $(\mathrm{FC}>0 \mathrm{padj}<0.05)$ Bd genes shared between setups. Significantly (C) downregulated (FC $<0$ padj $<0.05)$ and (D) upregulated (FC $>0$ padj < 0.05) Mo genes shared between setups ("Leaf 2 DPI", "Leaf 4 DPI" and "Root"). Transcript downregulation was calculated from mRNAseq data with DESeq2. 
Table 2. Selected defense-related Bd DEGs (padj < 0.05) during infection of leaves and roots by M. oryzae.

\begin{tabular}{|c|c|c|c|c|}
\hline Gene & Description & $\begin{array}{c}\log _{2} \text { FC- } \\
\text { Leaf } 2 \text { DPI }\end{array}$ & $\begin{array}{c}\log _{2} \mathrm{FC}- \\
\text { Leaf } 4 \text { DPI }\end{array}$ & $\begin{array}{c}\log _{2} \mathrm{FC}- \\
\text { Root }\end{array}$ \\
\hline BdiBd21-3.3G0465100 & $\mathrm{ABC}$ transporter a family member 2-like & 1.15 & 3.38 & 0.79 \\
\hline BdiBd21-3.3G0464900 & $\mathrm{ABC}$ transporter a family member 7-like & & 2.64 & 0.71 \\
\hline BdiBd21-3.2G0605400 & $\mathrm{ABC}$ transporter $\mathrm{b}$ family member 4-like & 2.15 & 5.08 & \\
\hline BdiBd21-3.2G0550500 & Pleiotropic drug resistance protein 3-like & 1.78 & 6.82 & 1.51 \\
\hline BdiBd21-3.5G0159100 & Anthranilate synthase component ii & 0.76 & 2.75 & 0.88 \\
\hline BdiBd21-3.3G0344500 & Chitinase 1 & & 2.70 & \\
\hline BdiBd21-3.2G0371800 & Cytochrome p450 71c4 & & 1.32 & 2.12 \\
\hline BdiBd21-3.1G0952300 & Disease resistance response & & 2.07 & \\
\hline BdiBd21-3.3G0144800 & Protein kinase xa21 & 1.77 & 2.41 & 1.24 \\
\hline BdiBd21-3.2G0545400 & LRR receptor-like serine threonine-protein kinase gso1 & & 1.59 & 1.79 \\
\hline BdiBd21-3.2G0632400 & Receptor-like protein kinase hsl1-like & & 3.15 & \\
\hline BdiBd21-3.1G0713100 & Proton-coupled amino acid transporter 3-like & 0.85 & 1.97 & 0.97 \\
\hline BdiBd21-3.2G0114800 & Pathogenesis related protein & 1.34 & 1.25 & \\
\hline BdiBd21-3.1G0165000 & Pathogenesis-related protein 1 & 6.06 & 8.19 & \\
\hline BdiBd21-3.4G0068000 & Pathogenesis-related protein 10 & & 3.47 & 3.75 \\
\hline BdiBd21-3.4G0043000 & Pathogenesis-related protein 5 & & 2.91 & \\
\hline BdiBd21-3.1G0772600 & Pathogenesis-related protein class i & & 5.29 & 4.47 \\
\hline BdiBd21-3.1G0772700 & Pathogenesis-related protein prb1-2-like & & 3.41 & 6.42 \\
\hline BdiBd21-3.3G0422200 & PR3-like 1 & & 2.63 & \\
\hline BdiBd21-3.3G0639500 & PR3-like 2 & & 3.96 & \\
\hline BdiBd21-3.4G0025400 & PR5-like & & 1.37 & \\
\hline BdiBd21-3.2G0600500 & PR5-like & & 2.28 & \\
\hline BdiBd21-3.1G0875700 & Pathogenesis-related protein Bet v I family & & 2.14 & \\
\hline BdiBd21-3.1G0054700 & NAC1 transcription factor & & 2.49 & \\
\hline BdiBd21-3.3G0652700 & MYB-related protein myb4-like & & 3.33 & \\
\hline BdiBd21-3.2G0688100 & Probable WRKY transcription factor 33-like & & 2.69 & \\
\hline BdiBd21-3.2G0615100 & Probable WRKY transcription factor 51-like & 1.45 & 3.44 & \\
\hline BdiBd21-3.3G0669400 & Ethylene-responsive transcription factor $1 \mathrm{a}$ & & 2.16 & \\
\hline BdiBd21-3.4G0171000 & Multicopper oxidase family expressed & 4.35 & 9.93 & 2.35 \\
\hline BdiBd21-3.4G0387000 & Cationic peroxidase spc4-like & 3.17 & 3.72 & \\
\hline BdiBd21-3.1G0233900 & Peroxidase & & 2.11 & \\
\hline BdiBd21-3.2G0563800 & Secologanin synthase-like & 0.57 & 0.54 & 1.08 \\
\hline
\end{tabular}

In total, we found 2135 Mo DEGs (Wald test, Benjamini-Hochberg adjustment, padj $<0.05$ ) in leaves at 2 DPI (1041 up and 1094 down), 3186 DEGs at 4 DPI (1710 up and 1476 down) and 1000 DEGs in infected roots (673 up and 327 down) (Figure 4; Table 1; Figure S5). A notable overlap of fungal DEGs was detected between the two foliar infections, with 346 up- and 498 downregulated genes shared, compared to 220 up- and 172 downregulated DEGs shared between leaf 2 DPI and root infection, and 498 up- and 203 downregulated DEGs shared between leaf 4 DPI and root infection. Overall, 142 genes were significantly downregulated in all setups, while 168 were consistently upregulated in all 
samples, including genes involved in fungal development, metabolism and pathogenicity (Figure 5C,D).

Expression of $D C L$ and $A G O$ genes was assessed in both organisms in leaves and roots, which showed that $B d D C L 1$ and MoDCL2 had the highest expression among the DCL family, and BdAGO3 and MoAGO3 among the AGO family (Figure 6).

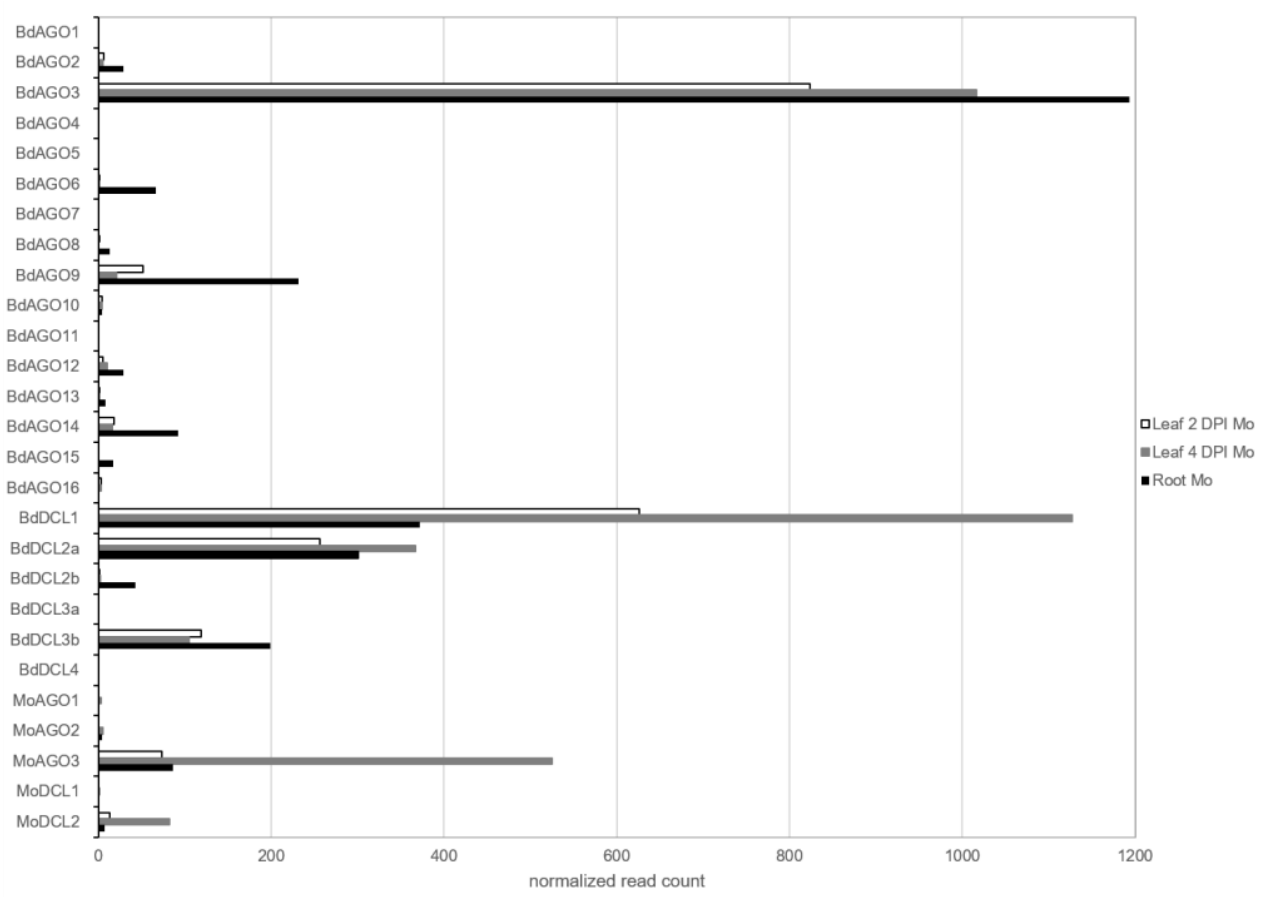

Figure 6. Expression of predicted ARGONAUTE (AGO) and DICER-like (DCL) during the interaction of $B$. distachyon and $M$. oryzae from mRNAseq results. Normalized read counts of each RNAi component were retrieved from DESeq2 analyses of infected datasets: leaf 2 DPI (white), leaf 4 DPI (grey) and root (black).

Interestingly, $B d A G O 9$, which is the closest homolog to AtAGO1 [35], was detected expressed in all three setups and had the highest read count of the AtAGO1-like clade. Moreover, $B d A G O 1, B d A G O 5$ and $B d A G O 15$ were only expressed in the root samples, while $B d A G O 4, B d A G O 7, B d A G O 11, B d D C L 3 a$ and $B d D C L 4$ were not detected in any of the datasets. Finally, the majority of $D C L$ and $A G O$ genes were not differentially regulated during the infection, with the exception of $B d D C L 3 b$ and $B d A G O 3$ (minor downregulation; $>-1 \log _{2} \mathrm{FC}$ ) and BdDCL1-2a and MoAGO3 (minor upregulation; $<1 \log _{2} \mathrm{FC}$ ) (Table S4).

\subsection{Gene Ontology Enrichment (GOE) and Defense-Related Gene Expression in Mo-Infected Bd}

GOE analysis using AgriGO v2 was performed on all Bd DEGs identified in leaves and roots by mRNAseq. In all three datasets, GO:0003824 (catalytic activity), GO:0016491 (oxidoreductase activity) and GO:0044710 (single-organism metabolic process) were enriched (Table S5). The highest number of Gene Ontology (GO) terms enrichment-in particular those related to various cellular metabolic processes-was recorded in leaves at 4 DPI, which corresponds to the necrotrophic fungal growth phase (Figure S6). Consistent with the extensive metabolic reprogramming highlighted in the GOE analysis, the highest number of DEGs also was observed in these samples. Specifically, we detected significant upregulation of known Bd defense response genes such as pathogenesis-related 1 (PR1), PR3 and PR5, receptor-like protein kinases and $M y b$ and WRKY transcription factors (Table 2). Only minor overlap was observed between defense-related genes expression patterns in the leaf 2 DPI and root samples. Three predicted PR proteins were upregulated in both 4 DPI and root setups, including PR10 and PRB1-2 $\left(\log _{2}\right.$ FC $>3$ in both, while not induced at 
2 DPI) and two were found significantly upregulated in the two foliar datasets, including PR1 (with a $\log _{2} \mathrm{FC}>6$ in these datasets and not induced in the roots).

\subsection{GOE and Gene Expression in Mo during Bd Infection}

Next, significantly up- and downregulated Mo genes were subjected to GOE analysis, showing the highest number of enriched GO terms in the root samples, including several terms relating to the interaction with the host (Table S6; Figure S7). Overall, many infectionrelated genes were significantly upregulated, including effectors AVR Pita1 and PWL2 (Pathogenicity toward Weeping Lovegrass) and NOXs (superoxide-generating NADPH oxidases) (Table 3).

Table 3. Selected significantly (padj <0.05) upregulated pathogenicity-/virulence-related M. oryzae genes during B. distachyon leaves and roots infection.

\begin{tabular}{|c|c|c|c|c|}
\hline Gene Stable ID & Description & $\begin{array}{c}\log _{2} \text { FC- } \\
\text { Leaf } 2 \text { DPI }\end{array}$ & $\begin{array}{c}\log _{2} \mathrm{FC}- \\
\text { Leaf } 4 \text { DPI }\end{array}$ & $\begin{array}{l}\log _{2} \mathrm{FC}- \\
\text { Root }\end{array}$ \\
\hline MGG_00750 & Cytochrome b-245 heavychain subunit beta & 2.23 & 2.12 & 2.80 \\
\hline MGG_01081 & Peroxin 14/17 & & 1.05 & \\
\hline MGG_01092 & Homocitrate synthase & 1.35 & & \\
\hline MGG_01748 & Putative protease & & 1.28 & \\
\hline MGG_02074 & Potassium/sodium efflux P-type ATPase & & 1.28 & 2.55 \\
\hline MGG_03356 & Ricin B lectin:Parallel beta-helix & & 7.08 & 5.06 \\
\hline MGG_04202 & MAS3 protein & 2.27 & & 2.75 \\
\hline MGG_04212 & L-ornithine 5-monooxygenase & 2.81 & 3.46 & 3.17 \\
\hline MGG_04301 & Pwl2 protein (PWL2) gene & 8.53 & & \\
\hline MGG_04545 & Cytochrome c peroxidase, mitochondrial & 3.26 & 0.95 & \\
\hline MGG_06011 & S-(Hydroxymethyl)glutathione dehydrogenase & & 2.53 & \\
\hline MGG_06648 & Hsp70 (LHS1) gene & 1.25 & & \\
\hline MGG_07514 & 3-oxoacyl-[acyl-carrier-protein] reductase & & 1.49 & \\
\hline MGG_07971 & Calcium-transporting ATPase 1 & & 1.80 & \\
\hline MGG_08315 & $\begin{array}{l}\text { 1-phosphatidylinositol-4,5-bisphosphate } \\
\text { phosphodiesterase delta-1 }\end{array}$ & 8.83 & 7.94 & \\
\hline MGG_08409 & Cellulose-growth-specific protein & & 3.78 & \\
\hline MGG_09022 & Transmembrane CFEM domain-containing protein & 5.41 & 7.42 & 7.88 \\
\hline MGG_09559 & Autophagy-related protein 9 & & 1.07 & \\
\hline MGG_09956 & PRO41 protein & 1.93 & 1.91 & 2.62 \\
\hline MGG_10097 & Intracellular hyphae protein 1 & 5.42 & & \\
\hline MGG_10510 & Ribonuclease T2 & 3.90 & & \\
\hline MGG_10730 & Potassium/sodium efflux P-type ATPase & & 4.75 & \\
\hline MGG_11882 & Sensor protein zRas & & 1.60 & 3.15 \\
\hline MGG_11899 & SH3 domain-containing protein & 1.93 & 1.52 & \\
\hline MGG_15370 & Metalloproteinase & 11.86 & & \\
\hline MGG_15972 & AVR-pik/pikm/pikp & 14.63 & 6.33 & \\
\hline
\end{tabular}

\section{5. sRNA Reprogramming in Bd and Mo at Early Infection Stages}

We assessed the expression of sRNAs in the same biological material utilized for mRNAseq. Before high-throughput next generation sequencing (NGS), multiplexed sRNA libraries were size selected for 15 to $35 \mathrm{nt}$ fragments (140-160 nt including TruSeq adapters). 
Single end sequencing on Illumina HiSeq1500 platform generated between 22 million (mil) and 38 mil reads each (Table S7). Quality check of raw reads was performed with FastQC, adapters were removed with cutadapt and reads were size selected between 18 to $32 \mathrm{nt}$. The organism of origin of the trimmed reads was predicted by mapping via Bowtie alignments to both Bd21-3 and Mo 70-15 genomes [44] (Bd21-3 v1.1 DOE-JGI, http://phytozome.jgi.doe.gov/). Ambiguous reads that could not be assigned to the organism of origin with high confidence were excluded to avoid miscalling. As expected, most reads in Mo-infected samples were assigned to Bd (with 100\% match) and not to the fungus (with at least two nucleotide mismatches) (Table S7). Size distribution of genome matched unique sRNA reads followed a similar trend throughout samples, with the Mo reads showing a minor peak around $20 \mathrm{nt}$ and $\mathrm{Bd}$ reads a considerable peak at $24 \mathrm{nt}$ (Figure 7A,B). Fungal unique sRNA reads were then compared among datasets derived from Mo axenic culture and Mo-infected plant tissues and classified as either exclusive or shared between samples (Figure 8A). Some 5708 Mo-sRNAs were identified in Mo-infected roots, of which $3263(57.15 \%)$ were found exclusively in the infected sample and not in the axenic culture. A total of $7215 \mathrm{Mo}$-sRNAs were identified in infected leaves during the biotrophic phase (2 DPI), of which 4399 (60.97\%) were found exclusively in infected samples. Finally, a total of 63,017 were found in infected leaf tissue during the necrotrophic phase (4 DPI), of which 46,212 (73.33\%) were exclusively found in infected samples.
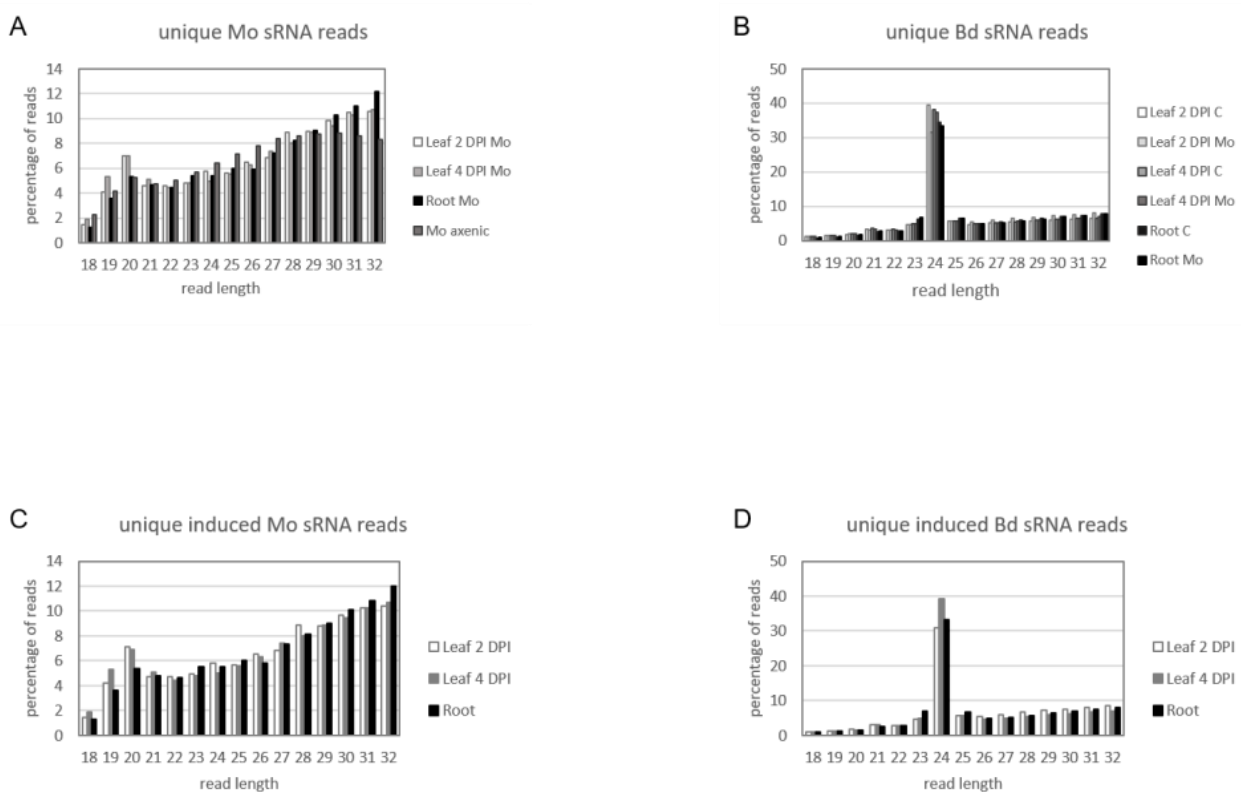

Figure 7. Size distribution of unique sRNA reads in the interaction of M. oryzae and B. distachyon. Relative size distribution (in percentage) of unique filtered sRNA reads assigned to (A) Mo or (B) Bd. Reads were assigned to either Mo or Bd only if aligning 100\% to the organism of origin genome and had at least two mismatches to the interacting organism genome. (C,D) Relative size distribution of unique filtered sRNA reads assigned to (C) Mo or (D) Bd and induced or increased in infected samples compared to controls (i.e., axenic fungal cultures and non-inoculated plants, respectively). Samples for sRNA sequencing by Illumina HiSeq1500 were taken from different setups: leaf biotrophic phase ("2 DPI"), leaf necrotrophic phase ("4 DPI") and root ("root").

Next, we compared unique Bd-sRNA reads in leaf and root samples from Mo-infected and mock-treated Bd (Figure 8B). A large number of sRNAs were found in infected tissues: 571,644 in leaves at 2 DPI, of which $326,657(72.24 \%)$ were specific for infection; 415,469 at 4 DPI, of which $265,172(69.06 \%)$ were specific for infection; and 597,158 Bd-sRNAs in infected roots, of which $346,259(77.92 \%)$ were specific for infection. These data show that the majority of unique sRNAs of both interacting organisms are expressed exclusively during the interaction, suggesting that they are relevant to the establishment and outcome 
of the disease. We further selected unique Bd-sRNAs that (i.) were either found exclusively in infected plant tissues or (ii.) showed higher reads in infected vs. mock-inoculated tissue. Interestingly, the size distribution of these induced Bd-sRNA did not show a change in length preference compared to the total unique reads (Figure $7 C, D$ ).

A
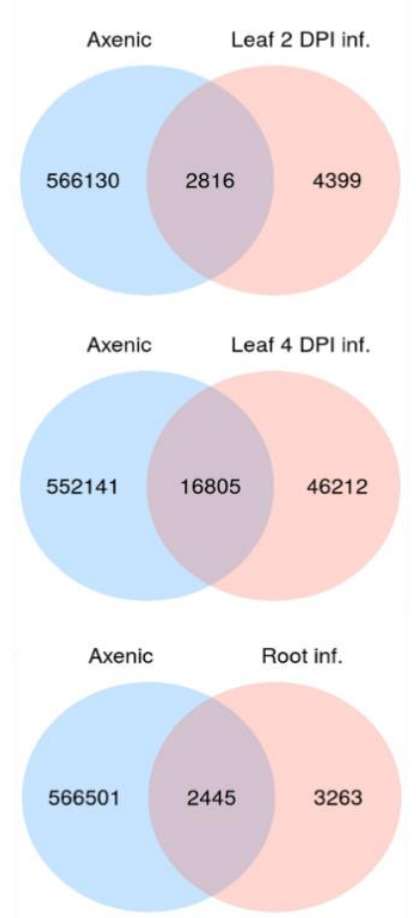

B

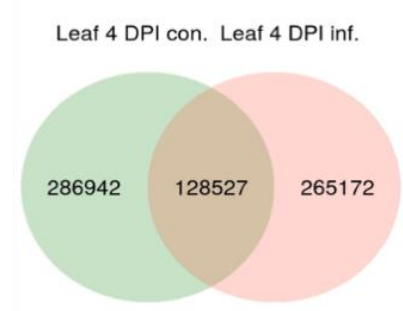

Leaf 2 DPI con. Leaf 2 DPI inf.

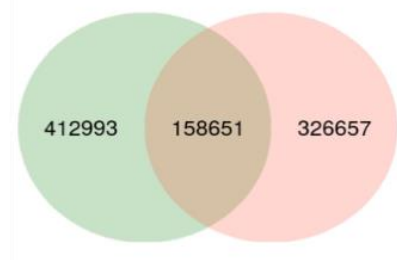

Root con. Root inf.

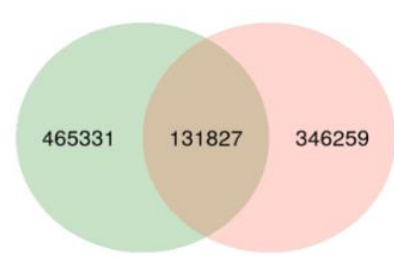

Figure 8. Venn diagrams of unique filtered sRNAs reads from M. oryzae and B. distachyon. (A) Venn diagram of Mo sRNA reads (18-32 nt) from axenic culture and Mo-infected Bd leaves (2 DPI, 4 DPI) and roots (4 DPI). (B) Venn diagram of Bd sRNA reads (18-32 nt) in non-infected and Mo-infected Bd leaves.

\subsection{Infection-Related $B d$ miRNAs}

Filtered Bd-sRNA reads were analyzed with Shortstack 3.8.5 to identify infectionrelated upregulation of potential plant miRNAs. The program identified 14 putative miRNA-generating loci in leaves at 2 DPI, 15 at 4 DPI and 16 in the roots. Matching predicted miRNA generating clusters in the uninfected samples were identified via their genomic coordinates, and numbers of total reads per cluster were compared between infected and uninfected samples to select exclusively expressed or upregulated miRNA loci. The selected clusters' sequences were aligned to known Bd miRNA stem loop precursor sequences obtained from the miRBase database: three known miRNAs were upregulated in leaves at 2 DPI, six at 4 DPI and four in the roots (Table 4). Structures of the miRNA precursors are shown in Figure S8. 
Table 4. B. distachyon miRNA identification.

\begin{tabular}{|c|c|c|c|c|}
\hline Setup & Cluster Number & miRNA & Cluster RPM & Mature miRNA Name \\
\hline \multirow{6}{*}{$\begin{array}{c}\text { Leaf } \\
2 \text { DPI }\end{array}$} & \multirow{2}{*}{3086} & \multirow{2}{*}{ Bdi-miR159b } & \multirow{2}{*}{118.27} & miR159b-3p.2 \\
\hline & & & & miR159b-3p.1 \\
\hline & 3421 & Bdi-MIR531 & 15.03 & MIR531 \\
\hline & 6495 & Bdi-MIR156b & 2.61 & miR156b-3p \\
\hline & \multirow{2}{*}{7687} & \multirow{2}{*}{ Bdi-miR9481b } & \multirow{2}{*}{19.12} & miR9481b -5p \\
\hline & & & & miR9481b-3p \\
\hline \multirow{9}{*}{$\begin{array}{l}\text { Leaf } \\
4 \mathrm{DPI}\end{array}$} & 7744 & Bdi-MIR156h & 13.79 & MIR156h-5p \\
\hline & \multirow{4}{*}{3312} & \multirow{4}{*}{ Bdi-MIR159b } & \multirow{4}{*}{184.31} & miR159b-3p.1 \\
\hline & & & & miR159b-3p.2 \\
\hline & & & & miR159b-5p.1 \\
\hline & & & & miR159b-5p.2 \\
\hline & 3162 & Bdi-MIR171d & 0.58 & MIR171d-3p \\
\hline & 7470 & Bdi-MIR529 & 30.80 & MIR529-5p \\
\hline & 2384 & Bdi-miR7723a & 13.02 & miR7723a-3p \\
\hline & 10592 & Bdi-MIR156d & 8.31 & MIR156d-5p \\
\hline \multirow{5}{*}{ Root } & \multirow{2}{*}{8229} & \multirow{2}{*}{ Bdi-MIR156i } & \multirow{2}{*}{2.87} & MIR156i-5p \\
\hline & & & & MIR156i -3p \\
\hline & 5121 & Bdi-MIR168 & 310.27 & MIR168-5p \\
\hline & 9081 & Bdi-MIR156d & 1.15 & miR156d-5p \\
\hline & 4330 & bdi-MIR9484 & 3.90 & MIR9484 \\
\hline
\end{tabular}

miRNA-generating clusters were identified with Shortstack in all datasets. Genomic coordinates were used to detect and compare the same loci in infected and control samples, and only clusters exclusive or increased in the infected samples were selected. Clusters and mature miRNAs were compared to known miRNA/miRNA precursor from miRBase. Abbreviation: RPM = reads per million.

\subsection{In Silico Prediction of Mo-sRNA Targeting Bd Transcripts}

sRNAs that were either exclusively produced or increased in infected tissues and had a normalized read count of at least five reads per million (RPM) were further investigated. Induced 20-22 nt sRNAs originating from non-coding regions of the Mo 70-15 genome (Figure 9) were selected as candidate cross-kingdom effectors with potential targets in the $\mathrm{Bd}$ transcriptome. Target prediction for these Mo-sRNAs was performed with psRNATarget using modified settings and a default score cut-off of 5.0. Target prediction data were then compared with the DEGs information derived from the concomitant mRNA sequencing. Of the total downregulated Bd transcripts, five were predicted to be targeted by Mo-sRNAs in the leaf 2 DPI setup, 1128 in the 4 DPI setup and 10 in the root (Table 5), with only one target shared between the root and the leaf 4 DPI datasets (Figure 10A). Predicted plant targets in leaves (4 DPI) included transcription factors such as transcriptional regulator algH, myb-related protein $\mathrm{Zm} 38$ and NIGTH1, along with aquaporin transporters and RNA helicases, including the putative $B d D C L 3 b$ (BdiBd21-3.2G0305700), along with resistance genes RGA3 (BdiBd21-3.2G0771500.1), RGA4 (BdiBd21-3.3G0396200.1) and RPP13-like protein 3 (BdiBd21-3.3G0776700.1) (Table 6). 


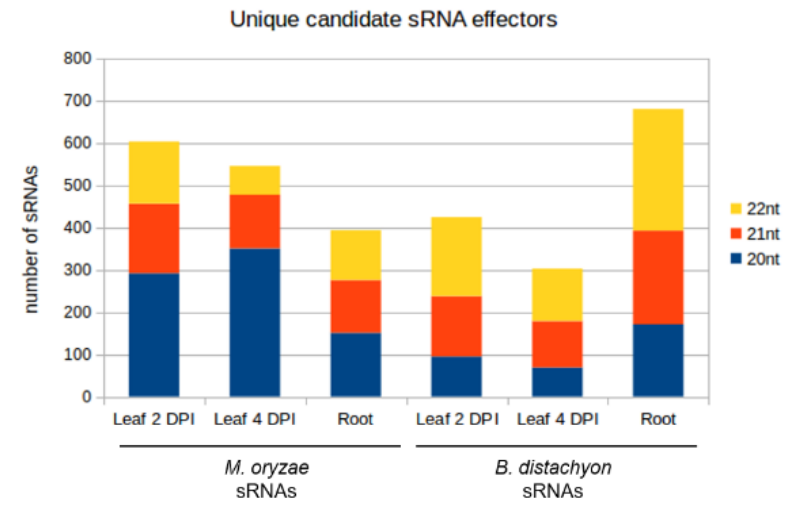

Figure 9. Size composition of unique candidate sRNA effectors from M. oryzae and B. distachyon. The number of unique reads is reported on the y-axis.

A

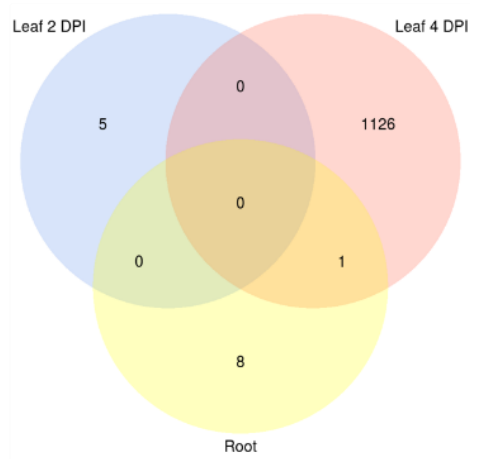

B

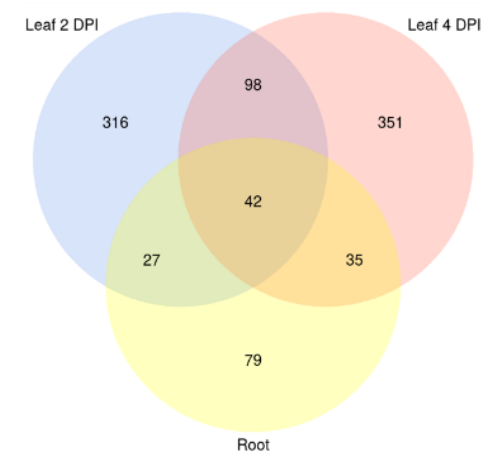

Figure 10. Venn diagram of downregulated predicted RNAi targets in M. oryzae and B. distachyon. Significantly downregulated (FC $<0$ padj $<0.05)(A) B d$ mRNA targets with complementarity to putative Mo sRNAs effectors shared between setups. (B) Mo mRNA targets with complementarity to putative Bd sRNA effectors. Setups: Leaf biotrophic phase (2 DPI) Leaf necrotrophic phase (4 DPI), and root. Transcript downregulation was assessed from mRNAseq data with DESeq2.

Table 5. Overview of the number of predicted cross-kingdom sRNA candidates (20-22 nt) and their corresponding target mRNAs after target downregulation confirmation $(\mathrm{FC}<0, \operatorname{padj}<0.05)$.

\begin{tabular}{|c|c|c|c|c|c|c|}
\hline & Setup & $\begin{array}{l}\text { Number of } \\
\text { sRNA } \\
\text { Candidates }\end{array}$ & $\begin{array}{c}\text { Number of sRNA } \\
\text { Candidates with } \\
\text { Downregulated } \\
\text { Targets }\end{array}$ & $\begin{array}{l}\text { Number of } \\
\text { Targets } \\
\text { Predicted }\end{array}$ & $\begin{array}{l}\text { Number of } \\
\text { Targets Down- } \\
\text { regulated }\end{array}$ & \\
\hline \multirow[t]{3}{*}{ Mo sRNAs } & Leaf 2 DPI & 604 & 7 & 25106 & 5 & Bd mRNAs \\
\hline & Leaf 4 DPI & 546 & 490 & 25415 & 1128 & \\
\hline & Root & 394 & 14 & 17335 & 10 & \\
\hline \multirow[t]{3}{*}{ Bd sRNAs } & Leaf 2 DPI & 424 & 314 & 4621 & 484 & Mo mRNAs \\
\hline & Leaf 4 DPI & 302 & 236 & 4431 & 527 & \\
\hline & Root & 681 & 263 & 6730 & 183 & \\
\hline
\end{tabular}


Table 6. Selection of Mo sRNA/Bd mRNA duplexes from different leaf and roots setups.

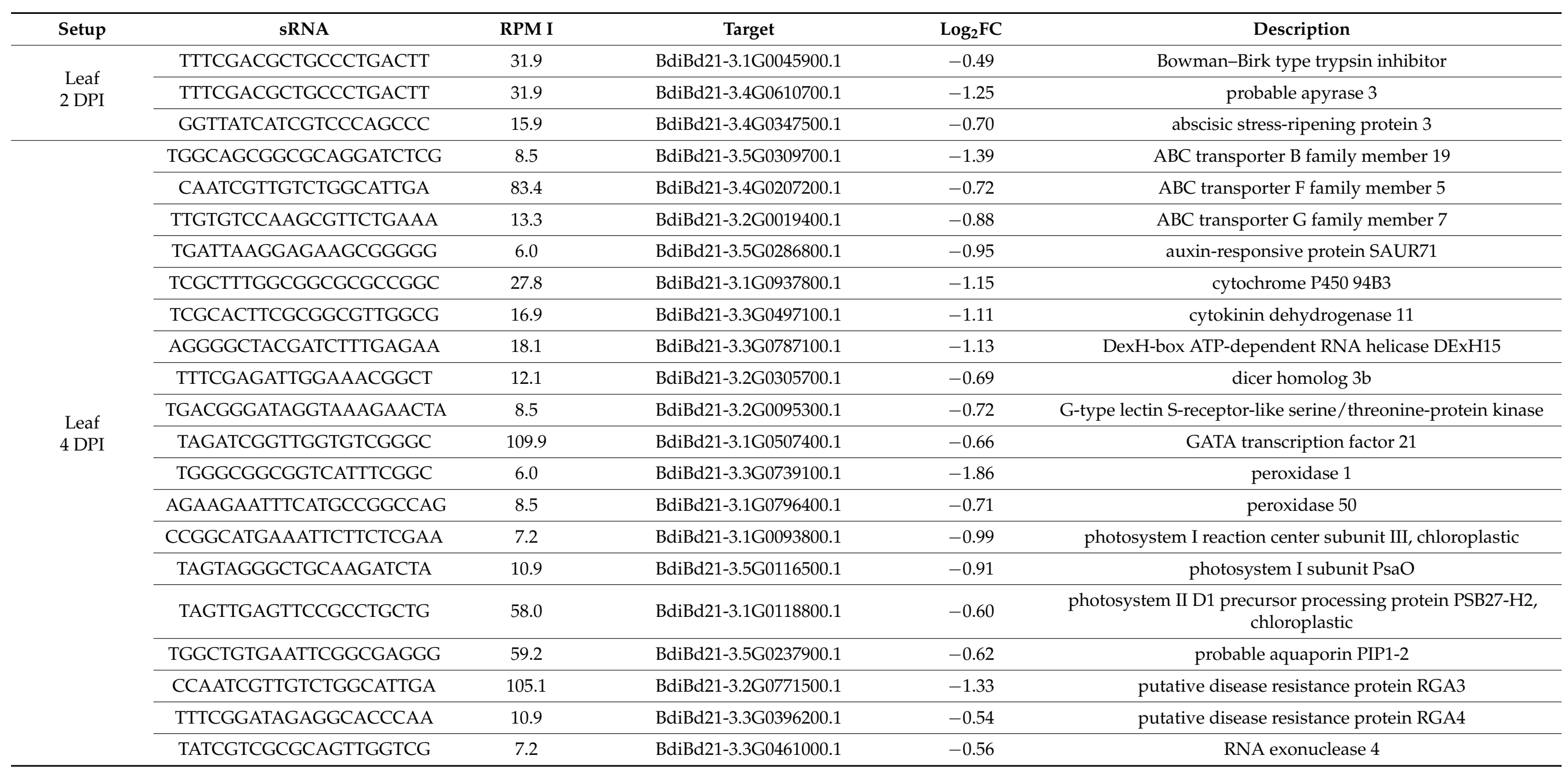


Table 6. Cont.

\begin{tabular}{|c|c|c|c|c|c|}
\hline Setup & sRNA & RPM I & Target & $\log _{2} \mathrm{FC}$ & Description \\
\hline & TGAGCCGGGGGTATAATCGG & 6.0 & BdiBd21-3.4G0029600.1 & -0.65 & stress-induced-phosphoprotein 1 \\
\hline & TGATTCGGCGGCAGGTCTGGC & 14.5 & BdiBd21-3.1G0170300.1 & -1.17 & transcription factor bHLH25 \\
\hline & TAAATACCGTCCCGGCAAGG & 9.7 & BdiBd21-3.4G0018600.1 & -0.66 & wall-associated receptor kinase 5 \\
\hline & TGACGGAGCTCGGCCTGGAA & 45.9 & BdiBd21-3.5G0304000.1 & -0.90 & wound-induced protein \\
\hline \multirow{3}{*}{ Root } & TAGGGTGGCCTGAATTATAGT & 10.4 & BdiBd21-3.2G0378400.1 & -0.74 & glycine-rich cell wall structural protein 1 \\
\hline & AGTATTCCGTCGTCGCCGTA & 20.7 & BdiBd21-3.3G0257600.1 & -0.78 & xyloglucan endotransglycosylase/hydrolase protein 8 \\
\hline & TGAACCAGCCGTTGAGTAAG & 10.4 & BdiBd21-3.3G0280200.1 & -0.55 & fatty acyl-CoA reductase 1 \\
\hline
\end{tabular}

Abbreviations: RPM = reads per million; $\mathrm{I}=$ infected sample; $\mathrm{FC}=$ fold change. 


\subsection{In Silico Prediction of Bd-sRNAs Targeting Mo Transcripts}

Given that plant-derived sRNAs can move into fungal pathogens during fungal infections [39,40], we further explored the possibility that Bd-sRNAs have corresponding downregulated Mo transcripts. In total, 20-22 nt Bd-sRNAs (Figure 9) that (i.) originate from the non-coding regions of the Bd21-3 genome, and (ii.) show a higher read count in the Mo-infected compared to non-infected sample were selected. We found 424, 302 and $681 \mathrm{Bd}-\mathrm{sRNA}$ in leaves at $2 \mathrm{DPI}$ and $4 \mathrm{DPI}$ and in roots, respectively, with predicted targets in the Mo transcriptome (Table 5). In the next step, we selected for targets found downregulated in the mRNAseq analysis, which further reduced the predicted Mo cksRNAs to 314 in leaves at 2 DPI, 236 at 4 DPI and 263 in roots, respectively, corresponding to potentially targeted mRNAs downregulated in leaves at 2 DPI (484), 4 DPI (527) and roots (183) (Table 5). Downregulated Mo targets include cell wall-related genes such as chitin deacetylase 1 (MGG_05023), cell wall protein MGG_09460 and virulence genes, such as CAP20 (MGG_11916) (Table 7). By comparing predicted Mo targets in infected tissues, we found a considerable overlap between leaf and root samples (42 Mo mRNAs) and between the two leaf samples (140 Mo mRNAs) (Table 7; Figure 10B).

Table 7. Selected M. oryzae mRNA targets of predicted cross-kingdom B. distachyon sRNAs from leaf and root setups.

\begin{tabular}{|c|c|c|c|c|c|c|c|}
\hline \multicolumn{3}{|c|}{ Predicted Target } & \multirow{2}{*}{$\begin{array}{l}\text { Target } \\
\text { ID }\end{array}$} & \multirow{2}{*}{$\begin{array}{c}\text { Target } \\
\text { Description }\end{array}$} & \multicolumn{3}{|c|}{$\log _{2} F C$} \\
\hline $\begin{array}{c}\text { Leaf } 2 \\
\text { DPI }\end{array}$ & $\begin{array}{l}\text { Leaf } \\
4 \text { DPI }\end{array}$ & Root & & & $\begin{array}{l}\text { Leaf } \\
2 \text { DPI }\end{array}$ & $\begin{array}{l}\text { Leaf } \\
4 \text { DPI }\end{array}$ & Root \\
\hline$x$ & $x$ & $x$ & MGG_02127 & alcohol oxidase & -5.46 & -2.53 & -3.11 \\
\hline$x$ & $x$ & $x$ & MGG_02695 & cysteine proteinase 1 & -4.72 & -1.35 & -2.46 \\
\hline$x$ & $x$ & $x$ & MGG_06494 & D-arabinitol 2-dehydrogenase & -5.52 & -1.16 & -3.21 \\
\hline$x$ & $x$ & $x$ & MGG_01386 & $\begin{array}{l}\text { FAD dependent oxidoreductase } \\
\text { superfamily protein }\end{array}$ & -5.19 & -2.16 & -4.51 \\
\hline$x$ & $x$ & $x$ & MGG_05981 & $\begin{array}{l}\text { glutamine amidotransferase subunit } \\
\text { pdxT }\end{array}$ & -4.79 & -2.34 & -4.25 \\
\hline$x$ & $x$ & $x$ & MGG_10400 & $\begin{array}{c}\text { GPI-anchored cell wall } \\
\text { beta-1,3-endoglucanase EglC }\end{array}$ & -0.99 & -2.05 & -2.11 \\
\hline$x$ & $x$ & $x$ & MGG_01361 & PHO85 cyclin-1 & -5.81 & -1.27 & -2.85 \\
\hline & $x$ & & MGG_15576 & DNA repair protein rhp51 & n.s. & -1.05 & n.s. \\
\hline & $x$ & & MGG_03587 & essential for mitotic growth 1 & n.s. & -0.60 & n.s. \\
\hline$x$ & $x$ & & MGG_04345 & cytochrome P450 17A1 & -4.40 & -1.06 & n.s. \\
\hline$X$ & & $x$ & MGG_03201 & acetyl-coenzyme A synthetase & -1.39 & 0.86 & -1.84 \\
\hline & $x$ & & MGG_09950 & $\begin{array}{l}\mathrm{C} 2 \mathrm{H} 2 \text { type zinc finger } \\
\text { domain-containing protein }\end{array}$ & n.s. & -1.49 & n.s. \\
\hline & $x$ & $x$ & MGG_16901 & ATP-dependent RNA helicase DBP2 & n.s. & -1.04 & -1.18 \\
\hline$X$ & $x$ & $X$ & MGG_07667 & autophagy-related protein 17 & -2.45 & -1.33 & n.s. \\
\hline$x$ & $x$ & $x$ & MGG_01391 & ent-kaurene oxidase & -3.90 & -2.44 & n.s. \\
\hline$x$ & $x$ & $x$ & MGG_11962 & G-protein coupled receptor & -5.75 & -3.42 & n.s. \\
\hline$x$ & $X$ & $x$ & MGG_04378 & integral membrane protein & -3.99 & -1.04 & n.s. \\
\hline$x$ & $x$ & $x$ & MGG_04935 & integral membrane protein & -3.58 & -1.40 & n.s. \\
\hline$X$ & $X$ & $X$ & MGG_03123 & MATE efflux family protein subfamily & -4.68 & -1.11 & n.s. \\
\hline$x$ & $x$ & $x$ & MGG_14872 & calpain-9 & -4.19 & -1.17 & n.s. \\
\hline
\end{tabular}


Table 7. Cont

\begin{tabular}{|c|c|c|c|c|c|c|c|}
\hline \multicolumn{3}{|c|}{ Predicted Target } & \multirow{2}{*}{$\begin{array}{l}\text { Target } \\
\text { ID }\end{array}$} & \multirow{2}{*}{$\begin{array}{c}\text { Target } \\
\text { Description }\end{array}$} & \multicolumn{3}{|c|}{$\log _{2} F C$} \\
\hline $\begin{array}{l}\text { Leaf } 2 \\
\text { DPI }\end{array}$ & $\begin{array}{l}\text { Leaf } \\
4 \text { DPI }\end{array}$ & Root & & & $\begin{array}{l}\text { Leaf } \\
2 \text { DPI }\end{array}$ & $\begin{array}{l}\text { Leaf } \\
4 \text { DPI }\end{array}$ & Root \\
\hline$x$ & $x$ & $x$ & MGG_09460 & cell wall protein & -4.72 & -3.92 & n.s. \\
\hline$x$ & $x$ & $x$ & MGG_03186 & 1,4-alpha-glucan-branching enzyme & -1.52 & n.s. & -1.36 \\
\hline$x$ & $x$ & $x$ & MGG_14154 & $\begin{array}{l}\text { RETRO5, retrotransposons MoTeR1s } \\
\text { and MoTeR2 }\end{array}$ & -6.04 & -1.15 & n.s. \\
\hline \multirow[t]{2}{*}{$x$} & & $x$ & MGG_06393 & serine/threonine-protein kinase ATG1 & -3.24 & n.s. & n.s. \\
\hline & $x$ & $x$ & MGG_04938 & $\begin{array}{c}\text { C-3 sterol dehydrogenase/C-4 } \\
\text { decarboxylase }\end{array}$ & n.s. & -1.85 & n.s. \\
\hline$x$ & $x$ & $x$ & MGG_10568 & sterol 24-C-methyltransferase & n.s. & n.s. & -1.24 \\
\hline$x$ & & $x$ & MGG_06371 & $\begin{array}{l}\text { pyruvate dehydrogenase E1 } \\
\text { component subunit alpha }\end{array}$ & n.s. & n.s. & -1.75 \\
\hline
\end{tabular}

$\mathrm{X}$ is assigned if the gene is predicted to be targeted by candidate sRNA in the corresponding setup. Abbreviations: $\mathrm{FC}=$ fold change; n.s. = not significant.

We searched the Pathogen-Host Interactions Database (PHI-base) for available information on loss-of-virulence mutants for the predicted Mo target genes. A list of downregulated predicted Mo targets and corresponding PHI-base phenotypes is shown in Table 8 . Of note, the predicted Mo genes are involved in virulence and pathogenicity, including CON7 transcription factor (MGG_05287) predicted to be targeted in the Moinfected root, the effector AvrPiz-t (MGG_09055) predicted to be targeted in the leaf at 4 DPI and the vacuolar glucoamylase SGA1 (MGG_01096) predicted to be targeted in the leaf at 2 DPI. Additionally, potential targets shared between more than one setup included (MGG_00620), Sso1 (MGG_04090) encoding a SNARE protein and YHM2 (MGG_07201) encoding mitochondrial DNA replication protein (2 DPI leaf vs. root), as well as MoATG17 (MGG_07667) encoding an autophagy-related protein (biotrophic vs. necrotrophic leaves), whose respective mutants are also known to be compromised in pathogenicity $[45,46]$ (Tables 7 and 8). 
Table 8. Predicted RNAi targets with known infection-impaired phenotypes in the corresponding M. oryzae knock-out (KO) mutants.

\begin{tabular}{|c|c|c|c|c|c|}
\hline Transcript ID & Gene ID & Description & Phenotype & Host Species & Reference Phi-Base \\
\hline MGG_00063T0 & AGL1 & glycogen debranching enzyme & reduced_virulence & Os_Hv & PHI:3814 \\
\hline MGG_00365T0 & MAGB & G alpha protein subunit & reduced_virulence & Os & PHI:83 \\
\hline MGG_00620T0 & MoDac & GlcNAc-6-phosphate deacetylase & reduced_virulence & Os & PHI:5471 \\
\hline MGG_01096T0 & SGA1 & vacuolar glucoamylase & loss_of_pathogenicity & Os_Hv & PHI:2138 \\
\hline MGG_01180T0 & MoSCAD3 & short-chain specific acyl-CoA dehydrogenase & reduced_virulence & Os_Hv & PHI:8929 \\
\hline MGG_01285T0 & Tpc1 & sranscription factor for Polarity Control 1 & reduced_virulence & Os_Hv & PHI:7317 \\
\hline MGG_01819T0 & Gph1 & phosphorylase & loss_of_pathogenicity/reduced_virulence & Os_Hv & PHI:2062/3815 \\
\hline MGG_02457T0 & RHO2 & Rho GTPase & reduced_virulence & Os & PHI:8752 \\
\hline MGG_02884T0 & MoFLP1 & fasciclin-like protein & reduced_virulence & Os_Hv & PHI:4231 \\
\hline MGG_03148T0 & TDG4 & trigalactosyldiacylglycerol-4 & reduced_virulence & Os_Hv & PHI:3811 \\
\hline MGG_03198T0 & TIG1 & histone deacetylation & loss_of_pathogenicity & Os_Hv & PHI:2002 \\
\hline MGG_03670T0 & SPM1 & subtilisin-like proteinase Spm1 & reduced_virulence & Os_Hv & PHI:2117 \\
\hline MGG_03860T0 & TPS1 & trehalose-6-phosphate synthase & loss_of_pathogenicity/reduced_virulence & Os_Hv & PHI:322/1064 \\
\hline MGG_04895T0 & ICL1 & isocitrate lyase & reduced_virulence & Os & PHI:305 \\
\hline MGG_05344T0 & MgSM1 & effector & increased_virulence & At & PHI:2118/5540 \\
\hline MGG_07667T0 & Moatg17 & autophagy-related protein 17 & loss_of_pathogenicity & Os_Hv & PHI:2083 \\
\hline MGG_08054T0 & MoChi1 & chitinase 1 & reduced_virulence & Os_Hv & PHI:8753/8806 \\
\hline MGG_08370T0 & gel3 & 1,3-beta-glucanosyltransferase & loss_of_pathogenicity & Os & PHI:6713 \\
\hline MGG_09471T0 & NTH1 & neutral trehalase & reduced_virulence & Os_Hv & PHI:123/775/794 \\
\hline MGG_10859T0 & MoLDS1 & heme peroxidase & reduced_virulence & Os & PHI:5189 \\
\hline MGG_11862T0 & $\mathrm{ABC} 4$ & $\mathrm{ABC}$ transporter & reduced_virulence/loss_of_pathogenicity & $\mathrm{Hv}$ & PHI:1017/2067 \\
\hline MGG_12122T0 & MoGSK1 & glycogen synthase kinase 1 & loss_of_pathogenicity & Os_Hv & PHI:7117 \\
\hline MGG_12814T0 & MoAP1 & BZIP domain-containing protein & loss_of_pathogenicity & Os_Hv & PHI:2142 \\
\hline MGG_17909T0 & ATG3 & autophagy-related protein 3 & loss_of_pathogenicity & Os & PHI:2071 \\
\hline MGG_05287T0 & CON7 & transcription factor CON7 & loss_of_pathogenicity & Os_Hv & PHI:2039 \\
\hline MGG_09055T0 & AvrPiz-t & avrpiz-tgene, effector protein & increased_virulence & Os & PHI:7896 \\
\hline
\end{tabular}

Information derived from Pathogen-Host Interactions Database (PHI-base) search. 


\section{Discussion}

Based on the work done to elucidate the function and 3D structure of Brachypodium distachyon AGO and DCL proteins published by Šečić et al. [35], we set out to investigate these RNAi machinery components in Magnaporthe oryzae. Mo has being extensively studied as a model for RNAi in fungi, and it is known to encode three AGOs, two DCLs and three RdRPs $[25,26]$. Interestingly, while the phylogeny with other fungal RNAi machineries such as N. crassa, Mucor circinelloides, Cryphonectria parasitica and Schizosaccharomyces pombe and the domain conservation have been reported, we found no information regarding the proteins' predicted interactome, subcellular localization and 3D protein structures, which would help elucidate the function and relevance of these proteins in vivo. We confirmed that all three fungal AGOs have the characteristic PAZ (Piwi Argonaut and Zwille) and PIWI (P-element Induced WImpy testis) domains: the first is involved in the recognition of the $3^{\prime}$ end of the guide sRNA molecule [47], while the second is an RNase H domain that confers AGOs the ability to cleave single-stranded RNAs complementary to the guide sRNA sequence [48]. A closer look at the PIWI domains via MSA confirmed the conservation of both the QF-V motif, involved in the sorting of sRNAs based on their sequence and secondary structure [49] and the DEDD catalytic tetrad, critical for the protein 'slicer' activity [48]. Similar to NcDCLs, both MoDCLs lacked predicted PAZ domain but differed from the N. crassa ortholog showing predicted dicer-dimer domains and lacking predicted dsRNA-specific ribonuclease and ds-RNA binding (DSRM) domains [27]. At this point of the analysis, no major differences were recorded among either Mo protein families, which would help elucidate the differences in both sRNA production and virulence reported in the RNAi KO mutants by Raman et al. [50]. Interestingly, protein subcellular localization helped shed additional light on MoAGO3 and MoDCL2 non-redundant roles within their families, with MoAGO3 predicted to localize exclusively in the nucleus, compared to MoAGO1, predicted in both the nucleus and the cytosol, and MoAGO2, predicted to localize in the cytosol and plastid. Moreover, we predicted MoDCL2 to exclusively localize in the cytosol, while MoDCL1 in the nucleus, confirming the distinct roles for these proteins in contrast with their redundant function N. crassa [51]. Additionally, predicted interactomes of MoAGOs showed significant differences between MoAGO1 vs. MoAGO2 and MoAGO3, which would point to a unique role of this protein. Specifically, the predicted interaction with an ATP-dependent RNA helicase DED1 (MGG_02762) and a Pumilio-family RNA-binding repeat protein (MGG_03158) would suggest a unique role for MoAGO1 in translation regulation [52,53]. KO mutants of these RNAi components have been previously characterized both for their sRNA accumulation patterns and their virulence on barley $[27,50]$. Except for $\Delta$ moago3, which did not sporulate and could not be further utilized, we tested the morphology and virulence of the available mutants in our newly established Bd pathosystems. While all five RNAi mutants showed unaltered growth, morphology and conidiation in axenic cultures, we detected significant differences in their ability to infect Bd tissues. Interaction between plants and its host pathogen is a dynamic system, influenced by several genetic and environmental factors which may alter the course of the infection and its reproducibility. The inoculation method proved to be critical for the assessment of virulence alterations, with the drop inoculation on detached leaves resulting in the most stable assay, and the spray on whole seedlings resulting in the most extreme phenotypes, with $\Delta$ modcl 2 and $\Delta$ modcl1/2 showing a complete loss of pathogenicity. These results both confirm and expand the key role of MoDCL2 first hypothesized by Raman and colleagues in a variety of fungal biological processes, including: sRNA biogenesis, fungal development and, as shown here, fungal virulence $[27,50]$. The reduction of virulence observed among RNAi mutants throughout the different setups further substantiate the importance of a fully functioning fungal silencing machinery and sRNAs generated for a successful infection of Bd tissues.

GOE analysis of Mo DEGs highlighted an enrichment of terms mainly related to fungal growth and development in all infected tissues. Especially in the root GO, terms related to interactions with other organisms, particularly via protein secretion, were found 
overrepresented. By assessing expression of protein effectors, we confirmed upregulation of known avirulence genes, including AVR Pita1 (coding for a metalloprotease) and PWL2 (a glycine-rich protein recognized by weeping lovegrass and finger millet $\mathrm{R}$ proteins), both found highly upregulated in the foliar biotrophic phase (2 DPI), and Avr-Pik/km/kp, upregulated at 2 and 4 DPI.

Genes involved in appressorium and penetration peg functionality were upregulated in all three setups, including WISH (Water wettability, Infection, Surface sensing and Hyper-conidiation) G-protein coupled receptor protein, whose $\mathrm{KO}$ renders the fungus unable to develop appressoria and establishes the infection on intact rice leaves [54] and superoxide-generating NADPH oxidases NOX1 (MGG_00750) and NoxD (MGG_09956). NOX1 is involved in cell wall biogenesis, affecting both chitin and melanin biosynthesis and deposition. $\mathrm{KO}$ of this gene resulted in a complete loss of appressorium-mediated cuticle penetration and failure of in planta proliferation even when inoculated onto wounded rice seedlings [55]. Similar defects were detected in rice leaves and roots inoculated with $\triangle$ noxD [56], confirming the key role played by NOX proteins not only in growth and sexual reproduction, but also in fungal virulence. $P L C 3$, significantly upregulated at both timepoints in leaves, is also required for normal conidiation and appressorium function, but contrary to NOXs normal infection was observed when $\Delta$ moplc3 was inoculated by infiltration into wounded rice leaves, excluding a function of PLC3 in fungal growth once inside host cells [57]. As expected, we detected in the later timepoint of the leaf infection (4 DPI) upregulation of genes known to be required for infection maintenance and expansion. One of these genes, S-(hydroxymethyl) glutathione dehydrogenase (MGG_06011), was exclusively upregulated in the 4 DPI dataset and it is known to be involved in the growth of infectious hyphae on barley leaves [58].

Overall, our analysis shows that Mo undergoes an extensive reprogramming during the establishment and maintenance of the infection and highlights the commonalities and differences in expression patterns depending on the inoculated tissue and the progression of the colonization. Of note and consistent with the detection of necrotrophic lesions on Bd roots (Figure S4), fungal reprogramming during the root infection is closer to the one reported in the foliar necrotrophic phase (with 701 DEGs shared between the setups) compared to the biotrophic phase (only 392 DEGs shared between the setups).

mRNA sequencing of Mo-infected and non-infected Bd leaves and root samples allowed for a systemic analysis and comparison of expression pattern alterations of $\mathrm{Bd}$ genes in response to the fungal pathogen. As predicted, the highest amount of DEGs was observed at 4 DPI in leaves, when the infection is spreading outside of the inoculation point and the fungus has switched to a more aggressive necrotrophic lifestyle $[5,12,59]$. The relatively low amount of DEGs in the other two setups is consistent with the early infection stages and the limited amount of fungal biomass both in the root and at 2 DPI in leaves. Interestingly, in all three setups the percentage of upregulated DEGs was higher compared to downregulated DEGS, with $96 \%$ upregulated in leaves at 2 DPI, $60.7 \%$ at 4 DPI and $69.5 \%$ in the roots, indicating an overall strong induction of gene expression. Consistent with the highest numbers of DEGs detected at 4 DPI, most GO terms reported in Table S5 belong to this dataset, with terms related to metabolic and biosynthetic processes being the most prevalent. Interestingly, all datasets had enriched terms related to oxidoreductase activities (GO:001649) confirmed also by the upregulation of BdiBd21-3.4G0171000, coding for a multicopper oxidase, in all setups, and BdiBd21-3.1G0233800 and BdiBd21-3.1G0233900, coding for peroxidases, in the leaf 4 DPI datasets. Peroxidases are commonly associated with plant responses to stress and specifically fungal infection, as they are involved in a variety of processes including the synthesis of phenols such as tannins and melanins, reactive oxygen species (ROS) removal, lignin biosynthesis and induction of defense responses by stimulating intracellular $\mathrm{Ca} 2+$ signaling [60]. Another gene upregulated in all three setups is secologanin synthase-like (BdiBd21-3.2G0563800), encoding an enzyme involved in the biosynthesis of monoterpenoid indole alkaloids (MIAs), also reported upregulated in Bd following F. pseudograminearum infection [61]. Expression of other 
defense-related genes was induced in one or more of our datasets, including known pathogenesis-related proteins, receptor kinases, transcription factors and $A B C$ transporters. Once again, 2 DPI and root samples were found overlapping in only a few of these genes. Examples of genes consistently found upregulated in all three setups are BdiBd213.3G0144800, encoding a protein kinase xa21 which confers resistance to Xanthomonas oryzae pv. oryzae race 6 [62], an ABC transporter A family member 2-like (BdiBd21-3.3G0465100) and the pleiotropic drug resistance protein 3-like (BdiBd21-3.2G0550500).

Interestingly, all $P R$ genes shown in Table 5 were upregulated in leaves at 4 DPI, while leaf 2 DPI and root PR protein expression patterns did not overlap, with only two (PR-like and PR1-like) upregulated at 2 DPI, and three (two PR1-like and PR10) in the root datasets. Similarly, the strongest and most widespread upregulation in the other pathogen sensing/defense-related genes was observed at $4 \mathrm{DPI}$, with an upregulation of transcription factors belonging to MYB, WRKY and NAC families consistent with the upregulation observed in Bd after F. pseudograminearum infection [61], and the knowledge that these families regulate a variety of plant responses, including those to biotic stresses [63-65]. In line with the considerable overlap in Mo gene expression patterns between leaf 4 DPI and root datasets, the majority of genes found upregulated in Bd roots $(80.9 \%)$ are also detected upregulated in leaves at 4 DPI, compared to $18 \%$ shared with the 2 DPI sample. Altogether, these results highlight differences in the upregulation of specific protein family members depending on the infected tissue and fungal lifestyle, while confirming the relevance of these families in response to Mo infections.

Candidate Bd miRNA-generating loci were identified with Shortstack from both control and infected filtered sRNA datasets. Given that the program-assigned cluster IDs are specific to the dataset analyzed and are not comparable between different files, we compared clusters based on their genomic coordinates, and further analyzed loci from the infected sample that had higher RPM (reads per million) than in control, or that were found exclusively in the presence of Mo. This resulted in the identification of 12 miRNA stem loop precursor sequences and 17 mature miRNAs across setups.

Specifically, we identified five mature miRNAs belonging to the MIR156 family, shown to be induced by F. oxysporum in Persicaria minor [66] and known to be induced by environmental stress, resulting in the cleavage of a SPL (SQUAMOSA promoter binding proteinlike) transcription factor and overall modulation of anthocyanin biosynthesis [34,67]. BdMIR529, also predicted to target this gene, was found upregulated at 4 DPI in our datasets. Another miRNA involved in the plant response to abiotic stress is miR159b, found upregulated during Mo leaf infection both at 2 and 4 DPI, and known to target two MYB transcription factors in cucumber (CSGAMYB1 and CsMYB29-like), involved in ABA signaling [68]. Finally, four additional miRNA families were detected as induced by Mo infection (MIR9484, miR9481b, MIR531 and miR7723a).

To establish the origin of the sRNA reads detected in the different leaf and root setups of the $\mathrm{Mo}-\mathrm{Bd}$ interaction, sRNAseq datasets from infected samples were aligned to both the Bd 21-3 and the Mo 70-15 genome. Only reads aligning without mismatches to Mo and with at least two mismatches to Bd were assigned to the fungus and vice-versa, only reads aligning without mismatches to $\mathrm{Bd}$ and with at least two mismatches to Mo were assigned to the plant. As expected from the low amount of Mo in infected samples from leaves at $2 \mathrm{DPI}$, most of the reads were assigned to $\mathrm{Bd}$, whereas higher levels of Mo reads were detected at 4 DPI (leaf) consistent with proliferating infection. All assigned reads were then filtered based on their read counts to select only reads either induced or upregulated in the datasets of infected tissues compared to uninfected tissues and axenic mycelia. We noted that most of the reads $(>50 \%)$ found in infected samples are specific and are not detected in healthy tissues and axenic culture, showing that sRNA production both in the plant and the fungus is strongly responsive to infection. It follows that sRNA datasets from healthy plants and axenic fungal culture do not represent the full diversity of infection-related sRNA communities. As an additional step, we selected for sRNAs that were not aligning to the coding sequences of the organism of origin. The reasoning behind 
this filtering step is that we avoided accidental mRNA degradation to be kept as candidate ck-sRNAs, and more important, removed the sRNA sequences more likely to play an endogenous role. Given that the size distribution of upregulated/induced sRNA reads did not show variation in peaks compared to the total sRNA reads, we decided to select 20-22 nt sRNAs (canonical length range for PTGS) for further analysis. Target prediction was carried out with psRNATarget, a web-based prediction software specifically designed for plant sRNA investigations, which allowed for the identification of complementary mRNA sequences in the interacting organism. In PTGS, sRNAs are loaded onto AGO proteins, which guide them towards a complementary mRNA sequence that will then be degraded or sequestered, resulting in reduced levels of the encoded protein. Knowing the expression levels of the predicted targets from the same biological samples used for the sRNA sequencing, we proceeded with further selection of candidate ck-sRNAs based on the significant downregulation of their mRNA targets. Most of the predicted Mo sRNA effectors in the 2 DPI leaf (biotrophic phase) and root samples did not pass this filtering step, as their predicted targets were either upregulated or had comparable expression levels in the corresponding control datasets. There are a few possible explanations as to why the potential targets would not be significantly downregulated in our mRNAseq datasets, including: (i.) the sRNA has not yet been transported throughout the tissue, so the downregulation occurs only at the penetration site, where the fungus is physically interacting with the plant cells, and that is masked by the upregulation in distal parts of the tissue; (ii.) the target mRNA is not cleaved, but its translation is inhibited by the RISC complex acting as a physical barrier, in which case the measurable effect would not be at the mRNA level but only at the protein level; and (iii.) the target is indeed cleaved, but concurrently with the downregulating effect of the sRNA, there is a stronger endogenous upregulation of the gene, leading to either similar levels of mRNA as the control, or even higher.

Comparison of lists with predicted fungal mRNA targets of Bd-sRNAs between the different setups highlights substantial target conservation between the leaf biotrophic and necrotrophic phases, with 140 predicted shared Mo targets between the two, and $42 \mathrm{Mo}$ targets conserved among all three setups. Subjecting the shortlisted predicted fungal target genes to a PHI-base survey for mutations in Mo with lethal or detrimental outcome, we found a clear indication for a reduction in pathogenicity or loss of virulence in respective KO mutants, including MoATG17 (MGG_07667), an autophagy-related protein whose KO impaired appressorium formation and function, resulting in a complete lack of disease symptoms on rice leaves [45]. Similarly, MoATG1 (MGG_06393) was also predicted to be targeted by Bd sRNAs and downregulated at 2 DPI, with Mgatg1 mutant reported by Liu et al. to be unable to infect rice and barley leaves [69]. Additionally, we predicted sRNAs targeting the avirulence effector AvrPiz-t (MGG_09055). AvrPiz-t suppresses rice PTI signaling pathway by targeting the E3 ubiquitin ligase APIP6 and suppressing its ligase activity, resulting in reduced flg22-induced ROS generation and overall enhanced susceptibility in vivo [70].

Interestingly, we detected Calpain-9 to be targeted in all three datasets and significantly downregulated in the foliar ones, both at 2 and 4 DPI. While downregulation in the root setup did not reach a significant padj value, targeting of this transcript would match the finding in the cotton- $V$. dahliae pathosystem, where the host was found to be expressing and exporting miRNAs to the infecting fungus to inhibit its virulence via the targeting of Clp-1 [39].

Additional predicted targets included integral membrane proteins (MGG_04378T0, MGG_04935T0), ergosterol biosynthesis enzymes (ERG6, MGG_10568T0; ERG26, MGG_ 04938T0) and fungal cell wall related genes, such as GPI-anchored cell wall beta-1,3- endoglucanase EglC (MGG_10400T0, targeted and significantly downregulated in all three datasets), cell wall protein MGG_09460T0 (targeted and significantly downregulated in both foliar samples), chitin deacetylase (MGG_08774T0) and chitinase 1 (MGG_08054T0). Targeting fungal membrane components and ergosterol homeostasis has already been proven to be a 
successful strategy in crop protection against fungal pathogens, both via the application of DMI (sterol demethylation inhibitors) fungicides [71] and with the RNAi-based HIGS (Host-Induced Gene Silencing) and SIGS (Spray Induced Gene Silencing) approaches, where artificial sRNAs are introduced in the plant either via transformation or external application is then transferred to the fungal cells during infection [72-74]. It is interesting to observe how the plant appears to have naturally evolved to produce sRNAs potentially able to target fungal essential and pathogenicity related genes. However, Mo is still able to progress its infection both in Bd leaves and roots, and the most likely factors behind this fungal success are the countermeasures it employs in this crosstalk, from the extensive reprogramming of gene expression to the release of effectors and sRNAs.

To substantiate the hypothesis that fungal sRNAs function as effectors to aid the establishment and maintenance of infection, we investigated the role of downregulated $\mathrm{Bd}$ targets. Targeting conserved sequences, such as ribosome- and photosynthesis-related ones, and hampering gene expression and biosynthetic processes would prove to be a more effective strategy than specific defense/immunity genes, which are more prone to mutate in the arms race between plants and pathogens.

We confirmed the targeting of a variety of RNA helicases genes, including BdDCL3b (BdiBd21-3.2G0305700), identified in our recent work [35] and involved in the preprocessing of sRNA precursor molecules involved in chromatin modification [75]. Specific plant targets included gene families involved in the plant response to both biotic and abiotic stresses, including hormone responsive proteins (BdiBd21-3.5G0286800.1, BdiBd21-3.4G0347500.1), transcription factors such as members of the GATA bHLH families (BdiBd21-3.1G0507400.1, BdiBd21-3.1G0170300.1), peroxidases (BdiBd21-3.3G0739100.1, BdiBd21-3.1G0796400.1, BdiBd21-3.3G0559700.1), disease resistance proteins (BdiBd21-3.2G0771500.1, BdiBd213.3G0396200.1) and ABC transporters (BdiBd21-3.5G0309700.1, BdiBd21-3.4G0207200.1, BdiBd21-3.2G0019400.1) [61,63,76,77] Interestingly, Brachypodium aquaporins (BdiBd213.5G0237900.1) were also downregulated and predicted targets of Mo sRNAs during the infection, consistent with the knowledge that aquaporins play a role in the interaction between plants and microbial pathogens, most likely by modulating both $\mathrm{H}_{2} \mathrm{O}$ availability and transport of ROS [78].

Altogether, the prediction of Mo ck-sRNAs and corresponding Bd targets involved in the plant response to biotic and abiotic stress paves the way for further validation of predicted sRNA/mRNA interactions, including: (i.) proof of target cleavage via RACE or degradome sequencing; (ii.) verification of sRNA-target interaction in transient expression systems such as leaves of Nicotiana benthamiana; (iii.) mutational KO strategies of predicted target genes and/or precursor loci of predicted ckRNAs; and (iv.) detection of direct association of sRNAs or their target mRNA with the respective fungal or plant AGO1-like protein by immunopurification techniques $[79,80]$.

\section{Materials and Methods}

\subsection{AGO and DCL Protein Analysis and 3D Structure Modeling}

Known ARGONAUTE and DICER-like protein sequences were downloaded from the NCBI database and analyzed following the workflow utilized for B. distachyon AGOs and DCLs [35]. The phylogenetic analysis and tree rendering were done by the Phylogeny.fr web server [81]. Multiple sequence alignment (MSA) of AGO PIWI domains was done using Clustal Omega [82,83] and visualized with the Mview multiple alignment viewer [84]. Protein domains were identified by using Simple Modular Architecture Research Tool (SMART) including PFAM domains in the search $[85,86]$ and visualized with the Illustrator for Biological Sequences (IBS) online illustrator [87]. Prediction of protein location was done using the plant subcellular localization integrative predictor (PSI) [88], and prediction of the interactome was done using the STRING database [89], excluding text mining as indication of putative interaction. Finally, AGOs and DCLs amino acid (aa) sequences were utilized for predicting the proteins' 3D structure utilizing SWISS-MODEL [90]. Predictions were selected for further validations based on the GMQE and QMEAN Z-score values [91]. 
PROCHECK $[92,93]$ and WHATCHECK [94] were used to check the stereochemical quality of the selected structures and calculate the Ramachandran Z-score [95]. Open-Source PyMOL (The Py-MOL Molecular Graphics System Version 2.4.0a0) was used for visualization of the predicted structures [96].

\subsection{Mo Mutants Cultivation and Inoculation}

The Magnaporthe oryzae wild type Mo 70-15 and mutants $\Delta$ moago1, $\Delta$ moago2, $\Delta$ moago3, $\Delta$ modcl1, $\Delta$ modcl 2 and $\Delta$ modcl $1 / 2$ obtained from N. Donofrio, Newark, NJ, USA, were grown as described [12]. Conidia germination and appressoria development was assessed by incubating conidial suspension $\left(2 \times 103\right.$ spores $\left.\mathrm{mL}^{-1}\right)$ in distilled water on poly-Llysine coated glass slides (Sigma-Aldrich, St. Louis, MO, USA) in a damp chamber at room temperature for $24 \mathrm{~h}$ and examined via inverted microscopy. Fungal stock was prepared on oatmeal agar (OMA) in a regime of $26{ }^{\circ} \mathrm{C} / 24{ }^{\circ} \mathrm{C}$ (day/night cycle) and a light intensity of $70 \mu \mathrm{mol} \mathrm{m}^{-2} \mathrm{~s}^{-1}$ photon flux density. Seeds of Brachypodium distachyon cv. 'Bd21-3' [97] were germinated in soil (Fruhstorfer Erde Typ T) and cultivated in a growth chamber at $22{ }^{\circ} \mathrm{C} / 18{ }^{\circ} \mathrm{C}$ (day/night cycle) with $60 \%$ relative humidity and a photoperiod of $240 \mu \mathrm{mol} \mathrm{m}{ }^{-2} \mathrm{~s}^{-1}$ photon flux density. Three methods were utilized to assess disease progression and phenotype of the mutants on leaves: (i.) spray infection of whole seedlings on three-week-old Bd plants with Mo conidia suspension of $120 \times$ 103 spores $\mathrm{mL}^{-1}$ in $0.002 \%$ Tween 20 and assayed on the second youngest leaf; (ii.) spray infection of second youngest detached leaves of three-week-old Bd plants with $250 \mu \mathrm{L}$ Magnaporthe oryzae conidia suspension $50 \times 103$ spores $\mathrm{mL}^{-1}$ in $0.002 \%$ Tween20; (iii.) drop inoculation on second youngest detached leaves of three-week-old Bd with $10 \mu \mathrm{L}$ of conidia solution (50,000 conidia/mL in $0.002 \%$ Tween water) on $1 \%$ agar plates. Control leaves/seedlings were mock-inoculated with $0.002 \%$ Tween water in all setups. Leaves were kept at $16 \mathrm{~h}$ light $\left(160 \mu \mathrm{mol} \mathrm{m}{ }^{-2} \mathrm{~s}^{-1}\right) / 8 \mathrm{~h}$ dark cycle at $22^{\circ} \mathrm{C} / 18^{\circ} \mathrm{C}$. Score disease progression and analysis of the necrotic spots was assayed 5 DPI via ImageJ software [98]. For root inoculation, sterilized seeds $(3 \% \mathrm{NaClO}$ for $15 \mathrm{~min}$, followed by three times $5 \mathrm{~min}$ washes in sterile water) of Bd21-3 were vernalized in the dark at $4{ }^{\circ} \mathrm{C}$ for two days on half strength MS medium [99] and then moved to a $16 \mathrm{~h}$ light $\left(160 \mu \mathrm{mol} \mathrm{m}^{-2} \mathrm{~s}^{-1}\right) / 8 \mathrm{~h}$ dark cycle at $22{ }^{\circ} \mathrm{C} / 18^{\circ} \mathrm{C}$. Roots of one-week-old seedlings were dip-inoculated in $1 \mathrm{~mL}$ of conidia solution $(125,000$ conidia $/ \mathrm{mL}$ in $0.002 \%$ Tween water) for $3 \mathrm{~h}$ and transplanted in a (2:1) mixture of vermiculite (Deutsche Vermiculite $\mathrm{GmbH}$, Sprockhövel, Germany) and Oil-Dri (Damolin, Mettmann, Germany). Control roots were mock-inoculated with $1 \mathrm{~mL}$ of $0.002 \%$ Tween water solution. Quantification of Mo DNA presence in roots was performed at 5 DPI by quantitative PCR based on the fungal actin (MoActin). The experiment was repeated two times, each time with $n=10$ roots per experimental group.

\subsection{Sample Preparation from Mo-Bd Interaction Sequencing}

Mo was grown on oatmeal agar (OMA) for two weeks at $26^{\circ} \mathrm{C}$ with $16 \mathrm{~h}$ light $/ 8 \mathrm{~h}$ dark cycles both for sampling of mycelium and conidia production. Samples from axenic cultures were collected by scraping a mixture of mycelia and spores from three plates, followed by immediate freezing in liquid nitrogen. For root inoculation, sterilized seeds ( $3 \% \mathrm{NaClO}$ for $15 \mathrm{~min}$, followed by three times $5 \mathrm{~min}$ washes in sterile water) of $\mathrm{Bd} 21-3$ were vernalized in the dark at $4{ }^{\circ} \mathrm{C}$ for two days on half strength MS medium and then moved to a $16 \mathrm{~h}$ light $\left(160 \mu \mathrm{mol} \mathrm{m}^{-2} \mathrm{~s}^{-1}\right) / 8 \mathrm{~h}$ dark cycle at $22{ }^{\circ} \mathrm{C} / 18{ }^{\circ} \mathrm{C}$. Roots of oneweek-old seedlings were dip-inoculated in $1 \mathrm{~mL}$ of conidia solution $(250,000$ conidia $/ \mathrm{mL}$ in $0.002 \%$ Tween water) for $3 \mathrm{~h}$, transplanted in a (2:1) mixture of vermiculite (Deutsche Vermiculite GmbH, Sprockhövel, Germany) and Oil-Dri (Damolin, Mettmann, Germany) and grown for an additional 4 days before harvesting. Control roots were mock-inoculated with $1 \mathrm{~mL}$ of Tween water solution. For leaf inoculation, third leaves of three-week-old Bd were detached and drop-inoculated with $10 \mu \mathrm{L}$ of conidia solution $(50,000$ conidia $/ \mathrm{mL}$ in $0.002 \%$ Tween water) on $1 \%$ agar plates. Control leaves were mock-inoculated with Tween 
water. Leaves were kept at $6 \mathrm{~h}$ light $\left(160 \mu \mathrm{mol} \mathrm{m}^{-2} \mathrm{~s}^{-1}\right) / 8 \mathrm{~h}$ dark cycle at $22{ }^{\circ} \mathrm{C} / 18{ }^{\circ} \mathrm{C}$ and collected for sequencing at 2 days post inoculation (DPI) and 4 DPI.

\subsection{RNA Extraction, Library Preparation and Sequencing}

Three roots or two leaves, respectively, were pooled per sample for RNA extraction and for each condition three pooled biological samples were prepared. Frozen tissue stored at $-80^{\circ} \mathrm{C}$ was ground in liquid nitrogen using mortar and pestle. Total RNA was isolated with ZymoBIOMICS TM RNA Mini Kit (Zymo Research, Irvine, CA, USA) according to the manufacturer's instructions. Quantity and integrity of the RNA were assessed with DropSense16/Xpose (BIOKÉ, Leiden, Netherlands) and Bioanalyzer 2100 (Agilent, Santa Clara, CA, USA), respectively. Purification of small and large RNAs into separate fractions was carried out using RNA Clean \& Concentrator TM -5 (Zymo Research, Irvine, CA, USA) and concentration and quality of the fractions were checked again, using the Agilent 2100 Bioanalyzer Pico Chip and the Qubit fluorometer (Invitrogen, Carlsbad, CA, USA) for the sRNA fraction. A total of $50 \mathrm{ng}$ of sRNA (17 to $200 \mathrm{nt}$ ) were used for cDNA library preparation with TruSeq ${ }^{\circledR}$ Small RNA Library Prep (Illumina, San Diego, CA, USA) and $1.5 \mu \mathrm{g}$ of large RNA were used for cDNA library preparation with TruSeq ${ }^{\circledR}$ Stranded mRNA (Illumina, San Diego, CA, USA). Constructed cDNA libraries of sRNAs were further size selected with BluePippin (Sage Science, Beverly, MA, USA) for fragments between 140 and $160 \mathrm{nt}$ (15-35 nt without adapters). Quality of polyA mRNA libraries was assessed using the Fragment AnalyzerTM Automated CE System (Advanced Analytical Technologies, Heidelberg, Germany). The Illumina HiSeq1500 sequencing platform was used to sequence the Illumina TruSeq ${ }^{\circledR}$ Small RNA libraries single end with $35 \mathrm{nt}$ read length and the Illumina TruSeq ${ }^{\circledR}$ Stranded mRNA libraries (paired-end [PE] sequencing, $70 \mathrm{nt})$ of all samples.

\subsection{Transcriptome Analysis}

Paired end sequenced cDNA reads of Illumina TruSeq ${ }^{\circledR}$ Stranded mRNA libraries were analyzed through the quality check in FastQC and alignment in the junction mapper HISAT2 [100]. Magnaporthe oryzae MG8 release 38 [101] and Brachypodium distachyon Bd21-3 v1.1 (DOE-JGI, http:/ / phytozome.jgi.doe.gov/) assemblies were utilized throughout this study as references. Htseq-count [102] and DESeq2 [103] were then used for read counting and differential gene expression calling (DGE) between the infected and control sample genes and to generate volcano plots. Heatmaps for selected DEGs were obtained with the pheatmap package for R [104]. Gene Ontology Enrichment (GOE) analysis on DEGs was done with AgriGO v2 [105]. Gene descriptions were integrated from the organism genome assembly, ENSEMBL Biomart, Phytozome and Blast2GO [106].

\section{6. sRNA Analysis, Prediction of Endo- and Cross-Kingdom sRNA}

The single end sequenced cDNA reads of Illumina TruSeq ${ }^{\circledR}$ Small RNA libraries were analyzed starting with quality check with FastQC [107] and trimming of adapter artifacts with cutadapt [108]. The alignment of the reads to reference genomes and transcriptomes of $\mathrm{Bd}$ and Mo was done using the short read aligner Bowtie [109]. Reads with a 100\% alignment to the genome of the organism of origin were selected, alongside the reads with at least two mismatches in the alignment to the target organism genome. Venn diagrams for sRNA and target overlaps were obtained with the VennDiagram package for R [110].

To identify interaction-related Bd sRNAs with endogenous function, both infected and control datasets were analyzed with ShortStack [111] to identify potential miRNA generating loci. Genomic coordinates and corresponding reads per million (RPM) of the identified clusters were compared between infected and control datasets to select clusters exclusively present or increased during infection. Both potential precursors and mature miRNAs deriving from these clusters were compared to known miRNA sequences, obtained from miRBase [112]. The structure of miRNA generating clusters was visualized with strucVis (version 0.4, Michael J. Axtell). 
Bioinformatics analysis of candidate ck-sRNAs was done as described in Zanini et al. [43]. Only sRNA reads of 20-22 nt originating from non-coding regions and with a higher count in the organism of origin control datasets compared to the infected ones were analyzed further for ck-sRNA effector identification by the target prediction software psRNATarget used with customized settings [113].

Expression levels obtained for each gene were used as confirmation of downregulation of predicted targets from the psRNATarget software. PHI-base, a collection of experimentally verified pathogenicity/virulence genes from fungal and microbial pathogens [114], was used to gather information regarding phenotype and virulence of fungal mutants carrying a mutation in the identified Mo gene targets.

\section{Conclusions}

In the present work, we analyzed and characterized the interaction between Brachypodium distachyon and Magnaporthe oryzae at different fungal lifestyles and infection sites, both from a transcriptomic and sRNA expression profiles' point of view. The pathosystem has been studied as a model for the effect of blast disease on staple crops leaves (e.g., rice, wheat and barley), owing to Bd's short maturation phase, smaller genome and space-saving production $[11,12,14]$. In addition to foliar infections, we also established and characterized the interaction and responses to $\mathrm{Bd}$ root colonization by Mo. Additional to the confirmation of the extensive reprogramming in both organisms throughout the interaction, our results support the possibility that major staple crops co-evolved mechanisms of RNA-based communication with their microbial pathogens. Based on concomitant deep sequencing of mRNA and sRNA fractions, our work provides the first indication of both plant and fungal sRNAs involvement in the communication between Magnaporthe oryzae with the model grass Brachypodium distachyon, further supporting the theory of ckRNAi participation in plant-pathogen interactions. Interestingly, sRNAs induced during infection setups show only partial overlap both among the different tissues (leaves, roots) and the different infection phases (leaf: biotrophic, necrotrophic), raising the possibility that ckRNAi in a given host-pathogen interaction exhibits tissue- and lifestyle-specificity.

Supplementary Materials: The following are available online at https://www.mdpi.com/1422-006 7/22/2/650/s1, Figure S1: Analysis of MoAGO and MoDCL protein sequences, Figure S2: Multiple sequence alignment of the PIWI domain of MoAGO proteins, Figure S3: Development of appressoria from conidia of Mo wt and RNAi mutants, Figure S4: Phenotypic analysis of Mo wt and RNA interference mutants, Figure S5: Heatmap for Mo and Bd DEG calling with DESeq2, Figure S6: Results of gene ontology enrichment (GOE) analysis for significantly DE Bd genes in the 4 DPI leaf setup, Figure S7: Results of gene ontology enrichment (GOE) analysis for significantly DE Mo genes in the root setup, Figure S8: Visual representation of the identified upregulated Bd clusters (miRNA precursors) structures, Table S1: Domain structures and coordinates of MoAGOs and MoDCLs as detected by SMART+PFAM search, Table S2: MoAGOs and MoDCLs protein localization prediction results by PSI, Table S3: Prediction of protein interactome for MoDCLs and MoAGOs, Table S4: Expression changes of AGOs and DCLs during the interaction of (A) B. distachyon and (B) M. oryzae from mRNAseq results, Table S5: Selection of significantly enriched Bd GO terms from 2 DPI, 4 DPI and root Bd DEG datasets, Table S6: Selection of significantly enriched Mo GO terms from 2 DPI, 4 DPI and root Mo DEG datasets, Table S7: Overview of total sRNA and mRNA reads in the Brachypodium distachyon-Magnaporthe oryzae interaction.

Author Contributions: Conceptualization, S.Z., E.Š., T.B. and K.-H.K.; Data curation, S.Z. and E.Š.; Formal analysis, S.Z. and E.Š.; Funding acquisition, K.-H.K.; Investigation, S.Z., E.Š., T.B., M.G., Y.Z. and J.K.; Methodology, S.Z., E.Š., T.B., J.K. and K.-H.K.; Project administration, S.Z. and K.-H.K.; Resources, K.-H.K.; Validation, S.Z., E.Š. and M.G.; Visualization, S.Z., E.Š. and M.G.; Writingoriginal draft, S.Z. and K.-H.K.; Writing-review \& editing, S.Z., E.Š., T.B., M.G., Y.Z., J.K. and K.-H.K. All authors have read and agreed to the published version of the manuscript.

Funding: This work was supported by the Deutsche Forschungsgemeinschaft (DFG) in the project RU5116 to K.-H.K. by the European Union's Horizon 2020 research and innovation programme under the Marie Skłodowska-Curie grant agreement No. 674964 to K.-H.K. and S.Z. 
Institutional Review Board Statement: Not applicable.

Informed Consent Statement: Not applicable.

Data Availability Statement: The data presented in this study are openly available in ArrayExpress, accessions E-MTAB-9985 and E-MTAB-9984.

Acknowledgments: We thank Elke Stein, Dagmar Biedenkopf and Christina Birkenstock for technical assistance. We thank John Vogel and the DOE-JGI for permission to use the Bd21-3 genome under early access conditions. We are grateful to Nicole M. Donofrio, Department of Plant \& Soil Sciences, University of Delaware, Newark, for sharing the Magnaporthe oryzae mutants. Brachypodium distachyon Bd21-3 is a gift of R. Sibout, INRA Verseille. A previous version of this manuscript has been released as a Pre-Print at BioRxiv (Zanini et al. 2019).

Conflicts of Interest: The authors declare no conflict of interest.

\section{References}

1. Dean, R.; Van Kan, J.A.L.; Pretorius, Z.A.; Hammond-Kosack, K.E.; Di Pietro, A.; Spanu, P.D.; Rudd, J.J.; Dickman, M.; Kahmann, R.; Ellis, J.; et al. The Top 10 fungal pathogens in molecular plant pathology. Mol. Plant Pathol. 2012. [CrossRef]

2. Donofrio, N.M.; Hu, J.; Mitchell, T.K.; Wilson, R.A. Facilitating the fungus: Insights from the genome of the rice blast fungus, Magnaporthe Oryzae. Genom. Plant-Assoc. Fungi Monocot Pathog. 2014. [CrossRef]

3. Fisher, M.C.; Henk, D.A.; Briggs, C.J.; Brownstein, J.S.; Madoff, L.C.; McCraw, S.L.; Gurr, S.J. Emerging fungal threats to animal, plant and ecosystem health. Nature 2012. [CrossRef] [PubMed]

4. Sesma, A.; Osbourn, A.E. The rice leaf blast pathogen undergoes developmental processes typical of root-infecting fungi. Nature 2004. [CrossRef]

5. Wilson, R.A.; Talbot, N.J. Under pressure: Investigating the biology of plant infection by Magnaporthe oryzae. Nat. Rev. Microbiol. 2009, 7, 185-195. [CrossRef]

6. Nalley, L.; Tsiboe, F.; Durand-Morat, A.; Shew, A.; Thoma, G. Economic and environmental impact of rice blast pathogen (Magnaporthe oryzae) alleviation in the United States. PLoS ONE 2016. [CrossRef] [PubMed]

7. Asibi, A.E.; Chai, Q.; Coulter, J.A. Rice blast: A disease with implications for global food security. Agronomy 2019, 9, 451. [CrossRef]

8. Osés-Ruiz, M.; Talbot, N.J. Cell cycle-dependent regulation of plant infection by the rice blast fungus Magnaporthe oryzae. Commun. Integr. Biol. 2017, 10, e1372067. [CrossRef] [PubMed]

9. Talbot, N.J. Having a blast: Exploring the pathogenicity of Magnaporthe grisea. Trends Microbiol. 1995, 3, 9-16. [CrossRef]

10. Marcel, S.; Paszkowski, U.; Sawers, R.; Oakeley, E.; Angliker, H. Tissue-adapted invasion strategies of the rice blast fungus Magnaporthe oryzae. Plant Cell 2010, 22, 3177-3187. [CrossRef]

11. Routledge, A.P.M.; Shelley, G.; Smith, J.V.; Talbot, N.J.; Draper, J.; Mur, L.A.J. Magnaporthe grisea interactions with the model grass Brachypodium distachyon closely resemble those with rice (Oryza sativa). Mol. Plant Pathol. 2004. [CrossRef]

12. Parker, D.; Beckmann, M.; Enot, D.P.; Overy, D.P.; Rios, Z.C.; Gilbert, M.; Talbot, N.; Draper, J. Rice blast infection of Brachypodium distachyon as a model system to study dynamic host/pathogen interactions. Nat. Protoc. 2008. [CrossRef] [PubMed]

13. Fitzgerald, T.L.; Powell, J.J.; Schneebeli, K.; Hsia, M.M.; Gardiner, D.M.; Bragg, J.N.; McIntyre, C.L.; Manners, J.M.; Ayliffe, M.; Watt, M.; et al. Brachypodium as an emerging model for cereal-pathogen interactions. Ann. Bot. 2015. [CrossRef] [PubMed]

14. Vogel, J.P.; Garvin, D.F.; Leong, O.M.; Hayden, D.M. Agrobacterium-mediated transformation and inbred line development in the model grass Brachypodium distachyon. Plant Cell. Tissue Organ Cult. 2006. [CrossRef]

15. Brutnell, T.P.; Bennetzen, J.L.; Vogel, J.P. Brachypodium distachyon and Setaria viridis: Model Genetic Systems for the Grasses. Annu. Rev. Plant Biol. 2015, 66, 465-485. [CrossRef] [PubMed]

16. Molnar, A.; Melnyk, C.W.; Bassett, A.; Hardcastle, T.J.; Dunn, R.; Baulcombe, D.C. Small silencing RNAs in plants are mobile and direct epigenetic modification in recipient cells. Science 2010, 328, 872-875. [CrossRef]

17. Borges, F.; Martienssen, R.A. The expanding world of small RNAs in plants. Nat. Rev. Mol. Cell Biol. 2015. [CrossRef]

18. Kehr, J.; Kragler, F. Long distance RNA movement. New Phytol. 2018. [CrossRef]

19. Fire, A.; Xu, S.; Montgomery, M.K.; Kostas, S.A.; Driver, S.E.; Mello, C.C. Potent and specific genetic interference by doublestranded RNA in caenorhabditis elegans. Nature 1998. [CrossRef]

20. Vaucheret, H.; Fagard, M. Transcriptional gene silencing in plants: Targets, inducers and regulators. Trends Genet. 2001. [CrossRef]

21. Castel, S.E.; Martienssen, R.A. RNA interference in the nucleus: Roles for small RNAs in transcription, epigenetics and beyond. Nat. Rev. Genet. 2013. [CrossRef] [PubMed]

22. Hamilton, A.J.; Baulcombe, D.C. A species of small antisense RNA in posttranscriptional gene silencing in plants. Science 1999, 286, 950-952. [CrossRef] [PubMed]

23. Baulcombe, D. RNA silencing in plants. Nature 2004. [CrossRef] [PubMed]

24. Vaucheret, H.; Vazquez, F.; Crété, P.; Bartel, D.P. The action of ARGONAUTE1 in the miRNA pathway and its regulation by the miRNA pathway are crucial for plant development. Genes Dev. 2004. [CrossRef] [PubMed] 
25. Kadotani, N.; Nakayashiki, H.; Tosa, Y.; Mayama, S. RNA silencing in the phytopathogenic fungus Magnaporthe oryzae. Mol. Plant-Microbe Interact. 2003. [CrossRef]

26. Murphy, D.; Dancis, B.; Brown, J.R. The evolution of core proteins involved in microRNA biogenesis. BMC Evol. Biol. 2008. [CrossRef]

27. Raman, V.; Simon, S.A.; Demirci, F.; Nakano, M.; Meyers, B.C.; Donofrio, N.M. Small RNA functions are required for growth and development of magnaporthe oryzae. Mol. Plant-Microbe Interact. 2017, 30, 517-530. [CrossRef]

28. Nunes, C.C.; Gowda, M.; Sailsbery, J.; Xue, M.; Chen, F.; Brown, D.E.; Oh, Y.Y.; Mitchell, T.K.; Dean, R.A. Diverse and tissueenriched small RNAs in the plant pathogenic fungus, Magnaporthe oryzae. BMC Genom. 2011, 12, 1-20. [CrossRef]

29. Wei, B.; Cai, T.; Zhang, R.; Li, A.; Huo, N.; Li, S.; Gu, Y.Q.; Vogel, J.; Jia, J.; Qi, Y.; et al. Novel microRNAs uncovered by deep sequencing of small RNA transcriptomes in bread wheat (Triticum aestivum L.) and Brachypodium distachyon (L.) Beauv. Funct. Integr. Genom. 2009. [CrossRef]

30. Wang, H.L.V.; Dinwiddie, B.L.; Lee, H.; Chekanova, J.A. Stress-induced endogenous siRNAs targeting regulatory intron sequences in Brachypodium. RNA 2015. [CrossRef]

31. Zhang, J.; Xu, Y.; Huan, Q.; Chong, K. Deep sequencing of Brachypodium small RNAs at the global genome level identifies microRNAs involved in cold stress response. BMC Genom. 2009, 10, 449. [CrossRef] [PubMed]

32. Franke, K.R.; Schmidt, S.A.; Park, S.; Jeong, D.H.; Accerbi, M.; Green, P.J. Analysis of Brachypodium miRNA targets: Evidence for diverse control during stress and conservation in bioenergy crops. BMC Genom. 2018. [CrossRef] [PubMed]

33. Bertolini, E.; Verelst, W.; Horner, D.S.; Gianfranceschi, L.; Piccolo, V.; Inzé, D.; Pè, M.E.; Mica, E. Addressing the role of micrornas in reprogramming leaf growth during drought stress in brachypodium distachyon. Mol. Plant 2013, 6, 423-443. [CrossRef] [PubMed]

34. Jeong, D.H.; Schmidt, S.A.; Rymarquis, L.A.; Park, S.; Ganssmann, M.; German, M.A.; Accerbi, M.; Zhai, J.; Fahlgren, N.; Fox, S.E.; et al. Parallel analysis of rna ends enhances global investigation of micrornas and target rnas of brachypodium distachyon. Genome Biol. 2013, 14, 1-22. [CrossRef] [PubMed]

35. Šečić, E.; Zanini, S.; Kogel, K.H. Further Elucidation of the Argonaute and Dicer Protein Families in the Model Grass Species Brachypodium distachyon. Front. Plant Sci. 2019, 10, 1-15. [CrossRef]

36. Buck, A.H.; Coakley, G.; Simbari, F.; McSorley, H.J.; Quintana, J.F.; Le Bihan, T.; Kumar, S.; Abreu-Goodger, C.; Lear, M.; Harcus, Y.; et al. Exosomes secreted by nematode parasites transfer small RNAs to mammalian cells and modulate innate immunity. Nat. Commun. 2014. [CrossRef]

37. Lamonte, G.; Philip, N.; Reardon, J.; Lacsina, J.R.; Majoros, W.; Chapman, L.; Thornburg, C.D.; Telen, M.J.; Ohler, U.; Nicchitta, C.V.; et al. Translocation of sickle cell erythrocyte MicroRNAs into Plasmodium falciparum inhibits parasite translation and contributes to malaria resistance. Cell Host Microbe 2012. [CrossRef]

38. Garcia-Silva, M.R.; Cura Das Neves, R.F.; Cabrera-Cabrera, F.; Sanguinetti, J.; Medeiros, L.C.; Robello, C.; Naya, H.; FernandezCalero, T.; Souto-Padron, T.; De Souza, W.; et al. Extracellular vesicles shed by Trypanosoma cruzi are linked to small RNA pathways, life cycle regulation, and susceptibility to infection of mammalian cells. Parasitol. Res. 2014. [CrossRef]

39. Zhang, T.; Zhao, Y.L.; Zhao, J.H.; Wang, S.; Jin, Y.; Chen, Z.Q.; Fang, Y.Y.; Hua, C.L.; Ding, S.W.; Guo, H.S. Cotton plants export microRNAs to inhibit virulence gene expression in a fungal pathogen. Nat. Plants 2016. [CrossRef]

40. Cai, Q.; Qiao, L.; Wang, M.; He, B.; Lin, F.M.; Palmquist, J.; Huang, S.D.; Jin, H. Plants send small RNAs in extracellular vesicles to fungal pathogen to silence virulence genes. Science 2018, 360, 1126-1129. [CrossRef]

41. Weiberg, A.; Wang, M.; Lin, F.M.; Zhao, H.; Zhang, Z.; Kaloshian, I.; Huang, H.D.; Jin, H. Fungal small RNAs suppress plant immunity by hijacking host RNA interference pathways. Science 2013, 342, 118-123. [CrossRef] [PubMed]

42. Wang, M.; Weiberg, A.; Dellota, E.; Yamane, D.; Jin, H. Botrytis small RNA Bc-siR37 suppresses plant defense genes by cross-kingdom RNAi. RNA Biol. 2017. [CrossRef]

43. Zanini, S.; Šečić, E.; Jelonek, L.; Kogel, K.H. A bioinformatics pipeline for the analysis and target prediction of rna effectors in bidirectional communication during plant-microbe interactions. Front. Plant Sci. 2018, 9, 1212. [CrossRef]

44. Zerbino, D.R.; Achuthan, P.; Akanni, W.; Amode, M.R.; Barrell, D.; Bhai, J.; Billis, K.; Cummins, C.; Gall, A.; Girón, C.G.; et al. Ensembl 2018. Nucleic Acids Res. 2018. [CrossRef]

45. Kershaw, M.J.; Talbot, N.J. Genome-wide functional analysis reveals that infection-associated fungal autophagy is necessary for rice blast disease. Proc. Natl. Acad. Sci. USA 2009. [CrossRef] [PubMed]

46. Giraldo, M.C.; Dagdas, Y.F.; Gupta, Y.K.; Mentlak, T.A.; Yi, M.; Martinez-Rocha, A.L.; Saitoh, H.; Terauchi, R.; Talbot, N.J.; Valent, B. Two distinct secretion systems facilitate tissue invasion by the rice blast fungus Magnaporthe oryzae. Nat. Commun. 2013, 4 , 1-12. [CrossRef]

47. Cenik, E.S.; Zamore, P.D. Argonaute proteins. Curr. Biol. 2011, 21, R446-R449. [CrossRef]

48. Song, J.J.; Smith, S.K.; Hannon, G.J.; Joshua-Tor, L. Crystal structure of argonaute and its implications for RISC slicer activity. Science 2004, 305, 1434-1437. [CrossRef] [PubMed]

49. Zhang, X.; Niu, D.D.; Carbonell, A.; Wang, A.; Lee, A.; Tun, V.; Wang, Z.; Carrington, J.C.; Chang, C.E.A.; Jin, H. ARGONAUTE PIWI domain and microRNA duplex structure regulate small RNA sorting in Arabidopsis. Nat. Commun. 2014. [CrossRef] [PubMed] 
50. Raman, V.; Simon, S.A.; Romag, A.; Demirci, F.; Mathioni, S.M.; Zhai, J.; Meyers, B.C.; Donofrio, N.M. Physiological stressors and invasive plant infections alter the small RNA transcriptome of the rice blast fungus, Magnaporthe oryzae. BMC Genom. 2013, 14. [CrossRef] [PubMed]

51. Kadotani, N.; Murata, T.; Nguyen, B.Q.; Adachi, Y.; Nakayashiki, H. Transcriptional control and protein specialization have roles in the functional diversification of two dicer-like proteins in Magnaporthe oryzae. Genetics 2008. [CrossRef] [PubMed]

52. Chuang, R.Y.; Weaver, P.L.; Liu, Z.; Chang, T.H. Requirements of the DEAD-box protein Ded1p for messenger RNA translation. Science 1997, 275, 1468-1471. [CrossRef] [PubMed]

53. Spassov, D.S.; Jurecic, R. The PUF Family of RNA-binding Proteins: Does Evolutionarily Conserved Structure Equal Conserved Function? IUBMB Life 2003, 55, 359-366. [CrossRef] [PubMed]

54. Sabnam, N.; Roy Barman, S. WISH, a novel CFEM GPCR is indispensable for surface sensing, asexual and pathogenic differentiation in rice blast fungus. Fungal Genet. Biol. 2017, 105, 37-51. [CrossRef]

55. Egan, M.J.; Wang, Z.Y.; Jones, M.A.; Smirnoff, N.; Talbot, N.J. Generation of reactive oxygen species by fungal NADPH oxidases is required for rice blast disease. Proc. Natl. Acad. Sci. USA 2007, 104, 11772-11777. [CrossRef]

56. Galhano, R.; Illana, A.; Ryder, L.S.; Rodríguez-Romero, J.; Demuez, M.; Badaruddin, M.; Martinez-Rocha, A.L.; Soanes, D.M.; Studholme, D.J.; Talbot, N.J.; et al. Tpc1 is an important Zn(II)2Cys6transcriptional regulator required for polarized growth and virulence in the rice blast fungus. PLoS Pathog. 2017, 13, e1006516. [CrossRef]

57. Choi, J.; Kim, K.S.; Rho, H.S.; Lee, Y.H. Differential roles of the phospholipase C genes in fungal development and pathogenicity of Magnaporthe oryzae. Fungal Genet. Biol. 2011, 48, 445-455. [CrossRef]

58. Zhang, Z.; Wang, J.; Chai, R.; Qiu, H.; Jiang, H.; Mao, X.; Wang, Y.; Liu, F.; Sun, G. An S-(hydroxymethyl)glutathione dehydrogenase is involved in conidiation and full virulence in the rice blast fungus Magnaporthe oryzae. PLoS ONE 2015. [CrossRef]

59. Tucker, S.L.; Besi, M.I.; Galhano, R.; Franceschetti, M.; Goetz, S.; Lenhert, S.; Osbourn, A.; Sesma, A. Common genetic pathways regulate organ-specific infection-related development in the rice blast fungus. Plant Cell 2010, 22, 953-972. [CrossRef]

60. Kawano, T. Roles of the reactive oxygen species-generating peroxidase reactions in plant defense and growth induction. Plant Cell Rep. 2003. [CrossRef]

61. Powell, J.J.; Carere, J.; Sablok, G.; Fitzgerald, T.L.; Stiller, J.; Colgrave, M.L.; Gardiner, D.M.; Manners, J.M.; Vogel, J.P.; Henry, R.J.; et al. Transcriptome analysis of Brachypodium during fungal pathogen infection reveals both shared and distinct defense responses with wheat. Sci. Rep. 2017. [CrossRef] [PubMed]

62. Song, W.-Y.; Wang, G.-L.; Chen, L.L.; Kim, H.-S.; Pi, L.-Y.; Holsten, T.; Gardner, J.; Wang, B.; Zhai, W.-X.; Zhu, L.-H.; et al. A receptor Kinase-Like Protein Encoded by the Rice Disease Ressitance Gene, Xa21. Science 1995, 270, 1804-1806. [CrossRef] [PubMed]

63. Ambawat, S.; Sharma, P.; Yadav, N.R.; Yadav, R.C. MYB transcription factor genes as regulators for plant responses: An overview. Physiol. Mol. Biol. Plants 2013. [CrossRef] [PubMed]

64. Bakshi, M.; Oelmüller, R. Wrky transcription factors jack of many trades in plants. Plant Signal. Behav. 2014. [CrossRef] [PubMed]

65. Murozuka, E.; Massange-Sánchez, J.A.; Nielsen, K.; Gregersen, P.L.; Braumann, I. Genome wide characterization of barley NAC transcription factors enables the identification of grain-specific transcription factors exclusive for the Poaceae family of monocotyledonous plants. PLoS ONE 2018. [CrossRef] [PubMed]

66. Samad, A.F.A.; Ali, N.M.; Ismail, I.; Murad, A.M.A. Analysis of miRNAs targeting transcription factors in Persicaria minor induced by Fusarium oxysporum. AIP Conf. Proc. 2016. [CrossRef]

67. Cui, L.G.; Shan, J.X.; Shi, M.; Gao, J.P.; Lin, H.X. The miR156-SPL9-DFR pathway coordinates the relationship between development and abiotic stress tolerance in plants. Plant J. 2014, 80, 1108-1117. [CrossRef]

68. Li, H.; Wang, Y.; Wang, Z.; Guo, X.; Wang, F.; Xia, X.J.; Zhou, J.; Shi, K.; Yu, J.Q.; Zhou, Y.H. Microarray and genetic analysis reveals that csa-miR159b plays a critical role in abscisic acid-mediated heat tolerance in grafted cucumber plants. Plant Cell Environ. 2016, 39, 1790-1804. [CrossRef]

69. Liu, X.H.; Lu, J.P.; Zhang, L.; Dong, B.; Min, H.; Lin, F.C. Involvement of a Magnaporthe grisea serine/threonine kinase gene, MgATG1, in Appressorium turgor and pathogenesis. Eukaryot. Cell 2007, 6, 997-1005. [CrossRef]

70. Park, C.H.; Chen, S.; Shirsekar, G.; Zhou, B.; Khang, C.H.; Songkumarn, P.; Afzal, A.J.; Ning, Y.; Wang, R.; Bellizzi, M.; et al. The magnaporthe oryzae effector avrpiz-t targets the RING E3 ubiquitin ligase APIP6 to suppress pathogen-associated molecular pattern-triggered immunity in ricesW OA. Plant Cell 2012. [CrossRef]

71. Bossche, H.V.; Lauwers, W.; Willemsens, G.; Marichal, P.; Cornelissen, F.; Cools, W. Molecular basis for the antimycotic and antibacterial activity of N-substituted imidazoles and triazoles: The inhibition of isoprenoid biosynthesis. Pestic. Sci. 1984. [CrossRef]

72. Koch, A.; Kumar, N.; Weber, L.; Keller, H.; Imani, J.; Kogel, K.H. Host-induced gene silencing of cytochrome P450 lanosterol $\mathrm{C} 14 \alpha$-demethylase-encoding genes confers strong resistance to Fusarium species. Proc. Natl. Acad. Sci. USA 2013. [CrossRef] [PubMed]

73. Koch, A.; Biedenkopf, D.; Furch, A.; Weber, L.; Rossbach, O.; Abdellatef, E.; Linicus, L.; Johannsmeier, J.; Jelonek, L.; Goesmann, A.; et al. An RNAi-Based Control of Fusarium graminearum Infections Through Spraying of Long dsRNAs Involves a Plant Passage and Is Controlled by the Fungal Silencing Machinery. PLoS Pathog. 2016. [CrossRef] [PubMed] 
74. Koch, A.; Höfle, L.; Werner, B.T.; Imani, J.; Schmidt, A.; Jelonek, L.; Kogel, K.H. SIGS vs. HIGS: A study on the efficacy of two dsRNA delivery strategies to silence Fusarium FgCYP51 genes in infected host and non-host plants. Mol. Plant Pathol. 2019. [CrossRef]

75. Margis, R.; Fusaro, A.F.; Smith, N.A.; Curtin, S.J.; Watson, J.M.; Finnegan, E.J.; Waterhouse, P.M. The evolution and diversification of Dicers in plants. FEBS Lett. 2006. [CrossRef]

76. Feller, A.; MacHemer, K.; Braun, E.L.; Grotewold, E. Evolutionary and comparative analysis of MYB and bHLH plant transcription factors. Plant J. 2011. [CrossRef]

77. Kang, J.; Park, J.; Choi, H.; Burla, B.; Kretzschmar, T.; Lee, Y.; Martinoia, E. Plant ABC Transporters. Arab. Book/Am. Soc. Plant Biol. 2011, 9, e0153. [CrossRef]

78. Afzal, Z.; Howton, T.C.; Sun, Y.; Mukhtar, M.S. The roles of aquaporins in plant stress responses. J. Dev. Biol. 2016, 9. [CrossRef]

79. Riley, K.J.; Yario, T.A.; Steitz, J.A. Association of argonaute proteins and microRNAs can occur after cell lysis. RNA 2012. [CrossRef]

80. Carbonell, A. Plant ARGONAUTES: Features, functions, and unknowns. Methods Mol. Biol. 2017. [CrossRef]

81. Dereeper, A.; Guignon, V.; Blanc, G.; Audic, S.; Buffet, S.; Chevenet, F.; Dufayard, J.F.; Guindon, S.; Lefort, V.; Lescot, M.; et al. Phylogeny.fr: Robust phylogenetic analysis for the non-specialist. Nucleic Acids Res. 2008. [CrossRef] [PubMed]

82. Goujon, M.; McWilliam, H.; Li, W.; Valentin, F.; Squizzato, S.; Paern, J.; Lopez, R. A new bioinformatics analysis tools framework at EMBL-EBI. Nucleic Acids Res. 2010. [CrossRef]

83. Sievers, F.; Wilm, A.; Dineen, D.; Gibson, T.J.; Karplus, K.; Li, W.; Lopez, R.; McWilliam, H.; Remmert, M.; Söding, J.; et al. Fast, scalable generation of high-quality protein multiple sequence alignments using Clustal Omega. Mol. Syst. Biol. 2011. [CrossRef] [PubMed]

84. Brown, N.P.; Leroy, C.; Sander, C. MView: A web-compatible database search or multiple alignment viewer. Bioinformatics 1998. [CrossRef] [PubMed]

85. Schultz, J.; Milpetz, F.; Bork, P.; Ponting, C.P. SMART, a simple modular architecture research tool: Identification of signaling domains. Proc. Natl. Acad. Sci. USA 1998. [CrossRef]

86. Letunic, I.; Bork, P. 20 years of the SMART protein domain annotation resource. Nucleic Acids Res. 2018. [CrossRef]

87. Liu, W.; Xie, Y.; Ma, J.; Luo, X.; Nie, P.; Zuo, Z.; Lahrmann, U.; Zhao, Q.; Zheng, Y.; Zhao, Y.; et al. IBS: An illustrator for the presentation and visualization of biological sequences. Bioinformatics 2015. [CrossRef]

88. Liu, L.; Zhang, Z.; Mei, Q.; Chen, M. PSI: A Comprehensive and Integrative Approach for Accurate Plant Subcellular Localization Prediction. PLoS ONE 2013. [CrossRef]

89. Szklarczyk, D.; Gable, A.L.; Lyon, D.; Junge, A.; Wyder, S.; Huerta-Cepas, J.; Simonovic, M.; Doncheva, N.T.; Morris, J.H.; Bork, P.; et al. STRING v11: Protein-protein association networks with increased coverage, supporting functional discovery in genome-wide experimental datasets. Nucleic Acids Res. 2019. [CrossRef]

90. Waterhouse, A.; Bertoni, M.; Bienert, S.; Studer, G.; Tauriello, G.; Gumienny, R.; Heer, F.T.; De Beer, T.A.P.; Rempfer, C.; Bordoli, L.; et al. SWISS-MODEL: Homology modelling of protein structures and complexes. Nucleic Acids Res. 2018. [CrossRef]

91. Benkert, P.; Biasini, M.; Schwede, T. Toward the estimation of the absolute quality of individual protein structure models. Bioinformatics 2011. [CrossRef] [PubMed]

92. Morris, A.L.; MacArthur, M.W.; Hutchinson, E.G.; Thornton, J.M. Stereochemical quality of protein structure coordinates. Proteins Struct. Funct. Bioinforma 1992. [CrossRef] [PubMed]

93. Laskowski, R.A.; MacArthur, M.W.; Moss, D.S.; Thornton, J.M. PROCHECK: A program to check the stereochemical quality of protein structures. J. Appl. Crystallogr. 1993. [CrossRef]

94. Hooft, R.W.W.; Vriend, G.; Sander, C.; Abola, E.E. Errors in protein structures. Nature 1996. [CrossRef] [PubMed]

95. Ramachandran, G.N.; Ramakrishnan, C.; Sasisekharan, V. Stereochemistry of polypeptide chain configurations. J. Mol. Biol. 1963. [CrossRef]

96. Delano, W.L. The PyMOL Molecular Graphics System, version 1.8; Schrödinger LLC: New York, NY, USA, 2002.

97. Vogel, J.; Hill, T. High-efficiency Agrobacterium-mediated transformation of Brachypodium distachyon inbred line Bd21-3. Plant Cell Rep. 2008. [CrossRef]

98. Schneider, C.A.; Rasband, W.S.; Eliceiri, K.W. NIH Image to ImageJ: 25 years of image analysis. Nat. Methods 2012. [CrossRef]

99. Murashige, T.; Skoog, F. A Revised Medium for Rapid Growth and Bio Assays with Tobacco Tissue Cultures. Physiol. Plant. 1962. [CrossRef]

100. Kim, D.; Langmead, B.; Salzberg, S.L. HISAT: A fast spliced aligner with low memory requirements. Nat. Methods 2015. [CrossRef]

101. Yates, A.D.; Achuthan, P.; Akanni, W.; Allen, J.; Allen, J.; Alvarez-Jarreta, J.; Amode, M.R.; Armean, I.M.; Azov, A.G.; Bennett, R.; et al. Ensembl 2020. Nucleic Acids Res. 2020. [CrossRef]

102. Anders, S.; Pyl, P.T.; Huber, W. HTSeq-A Python framework to work with high-throughput sequencing data. Bioinformatics 2015 [CrossRef] [PubMed]

103. Love, M.I.; Huber, W.; Anders, S. Moderated estimation of fold change and dispersion for RNA-seq data with DESeq2. Genome Biol. 2014. [CrossRef]

104. Kolde, R. Package 'pheatmap'. Bioconductor 2015, 7, 790.

105. Tian, T.; Liu, Y.; Yan, H.; You, Q.; Yi, X.; Du, Z.; Xu, W.; Su, Z. AgriGO v2.0: A GO analysis toolkit for the agricultural community, 2017 update. Nucleic Acids Res. 2017. [CrossRef] [PubMed] 
106. Conesa, A.; Götz, S.; García-Gómez, J.M.; Terol, J.; Talón, M.; Robles, M. Blast2GO: A universal tool for annotation, visualization and analysis in functional genomics research. Bioinformatics 2005. [CrossRef]

107. Andrews, S. FastQC:-A quality control tool for high throughput sequence data. Babraham Bioinforma 2010. Available online: http:/ / www.bioinformatics.babraham.ac.uk/projects/fastqc/ (accessed on 11 January 2018).

108. Martin, M. Cutadapt removes adapter sequences from high-throughput sequencing reads. EMBnet. J. 2011. [CrossRef]

109. Langmead, B. Aligning short sequencing reads with Bowtie. Curr. Protoc. Bioinforma 2010. [CrossRef]

110. Chen, H.; Boutros, P.C. VennDiagram: A package for the generation of highly-customizable Venn and Euler diagrams in R. BMC Bioinform. 2011. [CrossRef]

111. Johnson, N.R.; Yeoh, J.M.; Coruh, C.; Axtell, M.J. Improved placement of multi-mapping small RNAs. G3 Genes Genomes Genet. 2016. [CrossRef]

112. Griffiths-Jones, S.; Grocock, R.J.; van Dongen, S.; Bateman, A.; Enright, A.J. miRBase: microRNA sequences, targets and gene nomenclature. Nucleic Acids Res. 2006. [CrossRef] [PubMed]

113. Dai, X.; Zhao, P.X. PsRNATarget: A plant small RNA target analysis server. Nucleic Acids Res. 2011. [CrossRef] [PubMed]

114. Baldwin, T.K.; Winnenburg, R.; Urban, M.; Rawlings, C.; Koehler, J.; Hammond-Kosack, K.E. The Pathogen-Host Interactions Database (PHI-base) provides insights into generic and novel themes of pathogenicity. Mol. Plant-Microbe Interact. 2006. [CrossRef] [PubMed] 